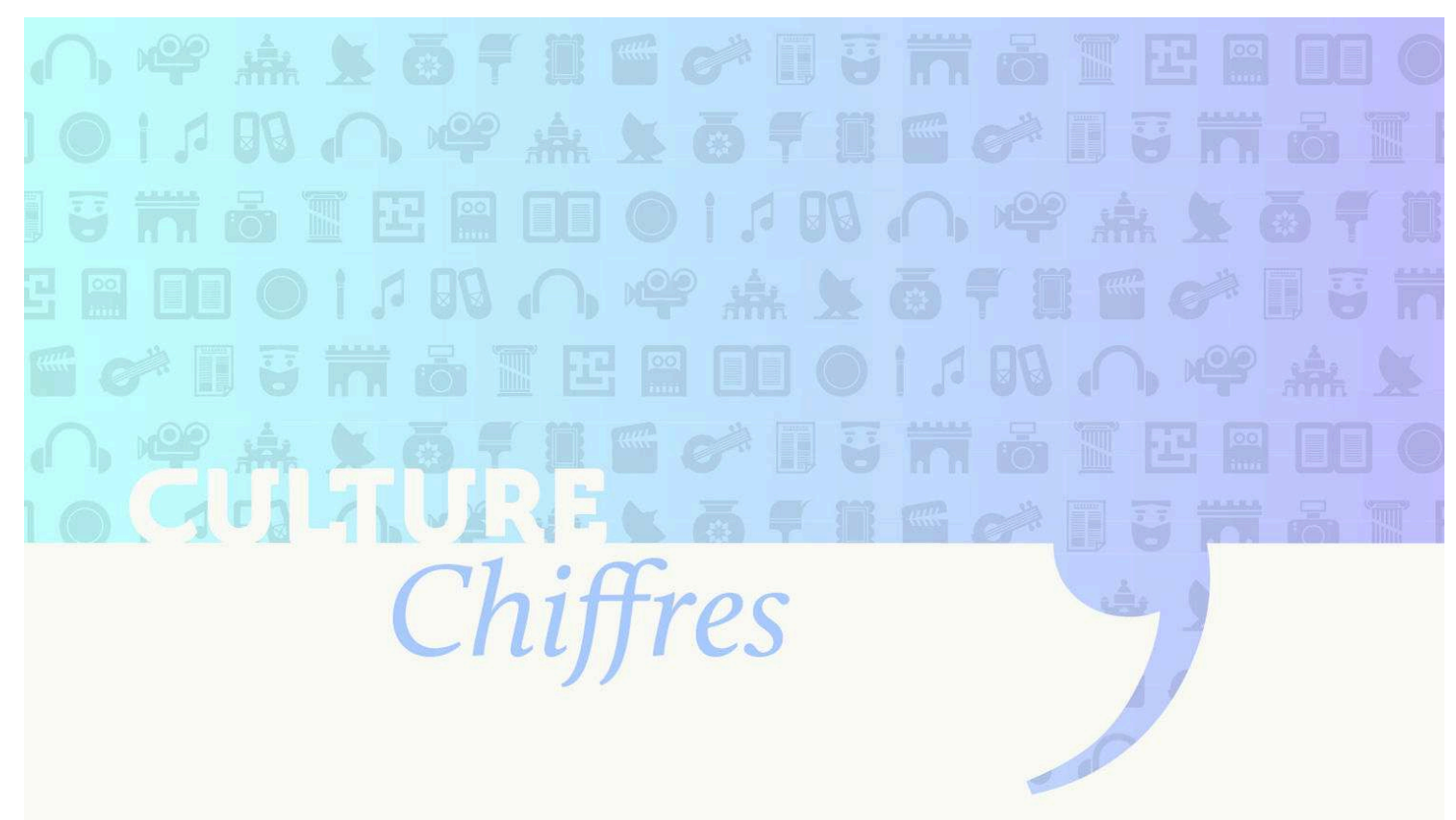

Revenus d'activité et niveaux de vie des professionnels de la culture

Marie Gouyon
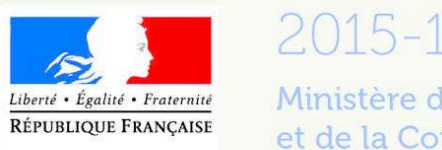

Ministère de la Culture

et de la Communication

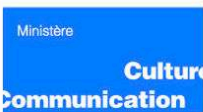

Département des études,

de la prospective

et des statistiques 


\section{Revenus d'activité et niveaux de vie des professionnels de la culture}

Income and living standards for cultural professionals

\section{Marie Gouyon}

Éditeur : Département des études, de la prospective et des statistiques

Lieu d'édition : Paris

Année d'édition : 2015

Date de mise en ligne : 21 septembre 2015

Collection : Culture chiffres

ISBN électronique : 9782111398245

\section{Sbooks}

http://books.openedition.org

\section{Édition imprimée}

Date de publication : 1 septembre 2015

Nombre de pages : 30

\section{Référence électronique}

GOUYON, Marie. Revenus d'activité et niveaux de vie des professionnels de la culture. Nouvelle édition [en ligne]. Paris : Département des études, de la prospective et des statistiques, 2015 (généré le 25 avril 2021). Disponible sur Internet : <http://books.openedition.org/deps/1063>. ISBN : 9782111398245. 


\title{
Revenus d'activité et niveaux de vie des professionnels de la culture
}

\author{
Marie Gouyon*
}

En France, 2,2\% des actifs exercent une profession culturelle. Au sein des professions culturelles, ils exercent des métiers très divers (artisans d'art, professeurs d'art, artistes et techniciens des spectacles, architectes ou cadres de l'édition, etc.) dont ils tirent des revenus dont la nature et les montants varient fortement d'une profession à l'autre (salaires, revenus d'indépendants, mais aussi revenus de remplacement tels que indemnités de chômage ou même, pour certains actifs, pensions de retraite). L'exploitation de plusieurs éditions de l'enquête Revenus fiscaux et sociaux de l'Insee permet de connaître les revenus annuels moyens tirés de l'activité ainsi que les revenus de complément.

Si les salaires annuels moyens perçus par les professionnels de la culture sont globalement équivalents à ceux de l'ensemble des actifs, les revenus de remplacement constituent en revanche une part importante de leurs ressources d'activité. Au total, les actifs des professions culturelles ont perçu en moyenne 26000 euros de revenus annuels d'activité entre 2005 et 2012. C'est $6 \%$ de plus que la moyenne de l'ensemble des actifs.

Toutefois, les caractéristiques sociodémographiques et les conditions d'emploi (qualification, temps de travail, etc.) des professionnels de la culture sont très différentes de celles des autres actifs. À caractéristiques identiques, les professionnels de la culture perçoivent en fait des revenus d'activité inférieurs de $26 \%$ à ceux des autres actifs.

La composition du ménage, l'histoire familiale, les revenus d'activités d'autres personnes du ménage, le plus souvent le conjoint, viennent compléter le revenu d'activité. Avec 30200 euros par an, les revenus d'activité des autres membres du ménage sont plus élevés $(+16 \%)$ pour les professionnels de la culture que pour les autres actifs. Les ménages des professionnels de la culture déclarent par ailleurs des revenus d'origine sociale, financière ou foncière supérieurs de $13 \%$, en moyenne, à ceux de l'ensemble des actifs (6 800 euros par an).

Rapporté à toutes les personnes composant le ménage, l'ensemble de ces revenus définit le niveau de vie. Entre 2005 et 2012, le niveau de vie annuel moyen des professionnels de la culture s'établit ainsi à 28300 euros, supérieur de $11 \%$ à celui des autres actifs ; mais là encore, à caractéristiques comparables il est inférieur de $12 \%$ à celui d'un actif exerçant une autre profession.

$\mathrm{Au}$ sein des professions culturelles, l'écart de revenus d'activité entre hommes et femmes est de $19 \%$ en faveur des hommes, de $29 \%$ dans l'ensemble des actifs en emploi. La prise en compte des revenus complémentaires du ménage, et notamment les revenus du conjoint, conduit à gommer l'écart de revenus d'activité entre les femmes et les hommes : le niveau de vie des femmes actives, qu'elles exercent une profession culturelle ou non, est très proche de celui des hommes.

* Département des études, de la prospective et des statistiques, ministère de la Culture et de la Communication. 
Artistes plasticiens, photographes et graphistes, artistes, cadres et techniciens des spectacles, journalistes et cadres de l'édition, auteurs littéraires et traducteurs, architectes, professeurs d'art ou encore artisans et ouvriers d'art, les professionnels de la culture tirent leurs revenus d'une ou plusieurs activités, salariées ou non, et de revenus de remplacement comme le chômage ou même, pour certains actifs, la retraite.

Toutefois, les revenus de l'activité professionnelle ne constituent qu'une part, plus ou moins importante, des moyens dont dispose un individu pour vivre : la composition du ménage, I'héritage familial, les revenus d'origine sociale, financière ou foncière peuvent constituer d'autres sources de revenus qui viennent compléter le revenu d'activité. La prise en compte de l'ensemble de ces revenus permet de situer le niveau de vie des professionnels de la culture par rapport à celui des autres groupes professionnels et de l'ensemble des actifs.

\section{Revenus d'activité}

Les revenus d'activité sont issus des activités professionnelles de la personne: ceux tirés de la profession culturelle qu'elle exerce au titre de son emploi principal, et ceux qu'elle perçoit éventuellement dans le cadre d'un emploi complémentaire, que cet emploi corresponde à l'exercice d'une profession culturelle ou non (par exemple un auteur littéraire qui occupe ponctuellement un emploi d'enseignant). De même, les indemnités de chômage perçues peuvent être associées à l'emploi que le professionnel de la culture occupe de façon salariée (par exemple pour un intermittent des spectacles) ou à un emploi complémentaire, qui peut être extérieur à la culture. Enfin, les pensions de retraite sont liées à une activité professionnelle qui peut être poursuivie après liquidation de la retraite (par exemple un retraité des activités d'architecture qui continue de proposer des prestations d'architecte) ou bien être étrangère au monde de la culture (un enseignant à la retraite qui continue d'avoir une activité professionnelle en tant qu'auteur).

\section{Moins de salariés dans les professions culturelles, avec des salaires équivalents à ceux de l'ensemble des actifs salariés}

Huit actifs sur dix exerçant une profession culturelle perçoivent des salaires (graphique 1 et tableau 1), selon l'enquête Revenus fiscaux et sociaux de l'Insee (voir «Sources», p. 23). C'est moins que pour l'ensemble des actifs, car les professions culturelles sont plus souvent exercées dans le cadre d'une activité indépendante: ainsi, seuls les deux tiers des professionnels des arts visuels (artistes plasticiens, photographes, graphistes, designers, etc.), des métiers d'art (par exemple facteurs d'orgue, lapidaires, vitraillistes...), des auteurs littéraires (écrivains, scénaristes, dialoguistes), des traducteurs et des architectes perçoivent des salaires. Certaines professions culturelles sont toutefois très majoritairement salariées : professeurs d'art (professeurs de chant au conservatoire, d'arts plastiques à l'École nationale des beaux-arts, etc.), métiers du spectacle, journalistes et cadres de l'édition, professionnels de l'archivage, de la conservation et de la documentation (conservateurs du patrimoine, bibliothécaires...).

En moyenne sur la période 2005-2012, les salaires annuels moyens perçus par un actif des professions culturelles sont équivalents à ceux de l'ensemble des actifs et s'élèvent à 23000 euros (graphique 1). Ils sont plus élevés pour les architectes (33700€), les cadres artistiques, de programmation et de production des spectacles (directeurs artistiques, producteurs, réalisateurs ou encore ingénieurs du son) (32 $200 €$ ) et pour les journalistes et les cadres de l'édition (31 $000 €$ ). Ils sont plus faibles pour les professeurs d'art (17 600 €) et pour les salariés des métiers d'art (17 $700 €)$. 


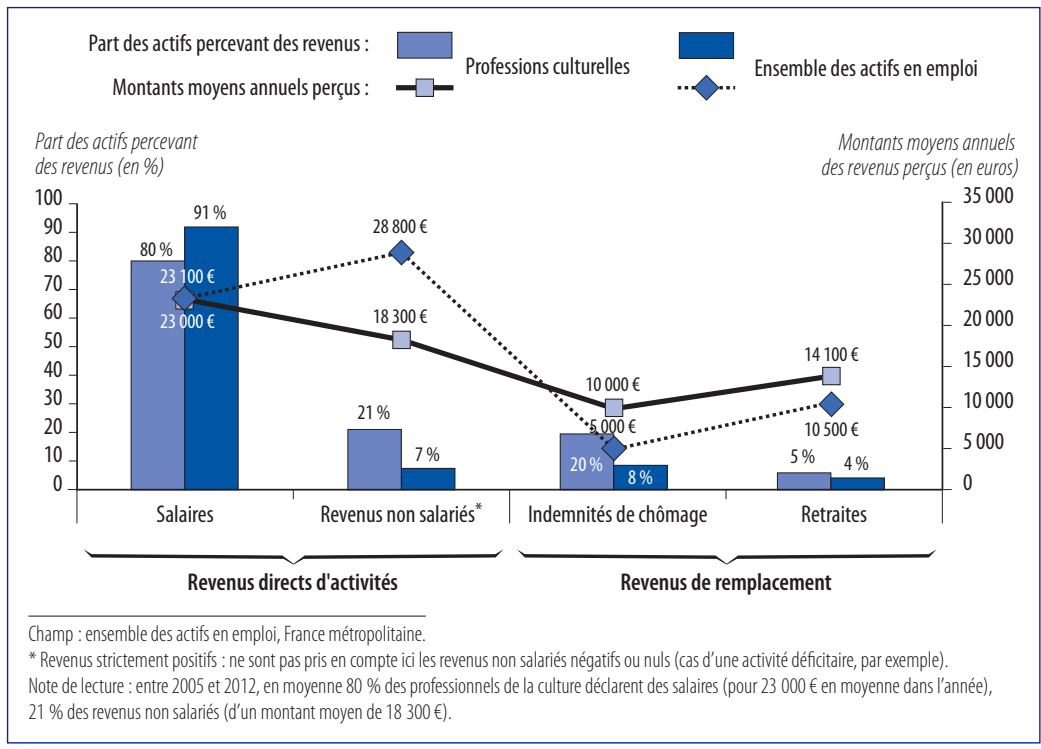

Source : Enquête Revenus fiscaux et sociaux, Insee/DEPS, Ministère de la Culture et de Communication, 2015

\section{Des revenus non salariés plus faibles}

Un professionnel de la culture sur cinq déclare des revenus d'indépendants ${ }^{1}$ strictement positifs ${ }^{2}$ (tableau 1 et graphique 1). Cette proportion dépasse un tiers pour les professionnels des arts visuels et métiers d'art, les auteurs littéraires et traducteurs ainsi que les architectes, pour lesquels l'exercice indépendant est fréquent. Les revenus prennent alors essentiellement la forme de revenus non commerciaux pour les architectes, les auteurs littéraires et traducteurs et pour les professionnels des arts visuels, et celle de revenus industriels et commerciaux dans les métiers d'art.

Les revenus d'indépendants sont nettement moindres dans les professions culturelles (en moyenne $18300 €$ contre $28800 €$ pour l'ensemble des indépendants), en raison notamment des revenus élevés atteints dans les professions libérales qui figurent parmi les professions les mieux rémunérées (médecins exerçant en cabinet, expertscomptables, notaires, avocats, etc.).

\section{Plus de $10 \%$ des professionnels des arts visuels et des auteurs littéraires et traducteurs cumulent salaires et revenus d'indépendants}

Dans l'ensemble de la population en emploi, le cumul de revenus directs d'activité de différentes natures est rare : seuls $2 \%$ des actifs perçoivent à la fois des salaires et des revenus d'indépendants (tableau 1). Le cumul est plus fréquent dans les professions culturelles (7\%), en particulier dans les professions à dominante artistique, telles que

1. Une partie des non-salariés déclarent leurs revenus d'indépendants en traitements et salaires - en particulier une partie des écrivains et des compositeurs -, ce qui explique que l'indépendance soit plus fréquente sous l'angle du statut exercé que sous celui du type de revenu d'activité perçu. 2. Les revenus peuvent être négatifs ou nuls en cas d'activité déficitaire. 
Tableau 1 - Revenus directs d'activité perçus en moyenne chaque année par les actifs, 2005-2012

\begin{tabular}{|c|c|c|c|c|c|c|c|}
\hline & \multicolumn{2}{|c|}{ Salaires } & \multicolumn{2}{|c|}{$\begin{array}{c}\text { Revenus } \\
\text { non salariés* }\end{array}$} & \multirow{2}{*}{$\begin{array}{c}\begin{array}{c}\text { Cumul } \\
\text { salaires } \\
\text { revenus } \\
\text { non salariés }\end{array} \\
\% \\
\begin{array}{c}\text { des } \\
\text { actifs }\end{array}\end{array}$} & \multicolumn{2}{|c|}{$\begin{array}{l}\text { Ensemble } \\
\text { des revenus } \\
\text { directs } \\
\text { d'activité }\end{array}$} \\
\hline & $\begin{array}{c}\% \\
\text { des } \\
\text { actifs }\end{array}$ & $\begin{array}{l}\text { Montant } \\
\text { moyen } \\
\text { (en euros) }\end{array}$ & $\begin{array}{c}\% \\
\text { des } \\
\text { actifs }\end{array}$ & $\begin{array}{c}\text { Montant } \\
\text { moyen } \\
\text { (en euros) }\end{array}$ & & $\begin{array}{c}\% \\
\text { des } \\
\text { actifs }\end{array}$ & $\begin{array}{l}\text { Montant } \\
\text { moyen } \\
\text { (en euros) }\end{array}$ \\
\hline Professions culturelles & 80 & 23000 & 21 & 18300 & 7 & 94 & 23700 \\
\hline $\begin{array}{l}\text { Professions des arts visuels } \\
\text { et des métiers d'art } \\
\text { Professionnels des arts visuels } \\
\text { Métiers d'art }\end{array}$ & $\begin{array}{l}65 \\
66 \\
63\end{array}$ & $\begin{array}{l}18800 \\
19000 \\
17700\end{array}$ & $\begin{array}{l}34 \\
35 \\
31\end{array}$ & $\begin{array}{l}15500 \\
16100 \\
11800\end{array}$ & $\begin{array}{r}11 \\
12 \\
5\end{array}$ & $\begin{array}{l}90 \\
90 \\
90\end{array}$ & $\begin{array}{l}19500 \\
20100 \\
16500\end{array}$ \\
\hline $\begin{array}{l}\text { Professions du spectacle } \\
\text { Artistes des spectacles } \\
\text { Cadres artistiques, de programmation } \\
\text { et de production des spectacles } \\
\text { Techniciens des spectacles }\end{array}$ & $\begin{array}{r}94 \\
95 \\
89 \\
96\end{array}$ & $\begin{array}{l}22800 \\
18200\end{array}$ & $\begin{array}{r}10 \\
4\end{array}$ & 15300 & $\begin{array}{l}5 \\
8\end{array}$ & $\begin{array}{l}96 \\
97\end{array}$ & $\begin{array}{l}23400 \\
18400\end{array}$ \\
\hline $\begin{array}{l}\text { Professions littéraires } \\
\text { Journalistes et cadres de l'édition } \\
\text { Auteurs littéraires et traducteurs }\end{array}$ & $\begin{array}{l}85 \\
94 \\
64\end{array}$ & $\begin{array}{l}28200 \\
31000 \\
18500\end{array}$ & $\begin{array}{r}17 \\
9 \\
34\end{array}$ & $\begin{array}{l}16900 \\
22300\end{array}$ & $\begin{array}{r}8 \\
6 \\
13\end{array}$ & $\begin{array}{l}94 \\
97 \\
87\end{array}$ & $\begin{array}{l}28500 \\
30800 \\
22500\end{array}$ \\
\hline Architectes & 67 & 33700 & 35 & 35800 & 7 & 95 & 36700 \\
\hline $\begin{array}{l}\text { Professions de l'archivage, } \\
\text { de la conservation } \\
\text { et de la documentation }\end{array}$ & 99 & 26300 & 1 & & 1 & 100 & 26400 \\
\hline Professeurs d'art & 90 & 17600 & 13 & 9700 & 6 & 97 & 17600 \\
\hline Ensemble des actifs en emploi & 91 & 23100 & 7 & 28800 & 2 & 96 & 24000 \\
\hline \multicolumn{8}{|c|}{$\begin{array}{l}\text { Champ : ensemble des actifs en emploi, France métropolitaine. } \\
\text { * Revenus strictement positifs : ne sont pas pris en compte ici les revenus non salariés négatifs ou nuls (cas d'une activité défícitaire, par exemple). } \\
\text { Note : en grisé, résultats non significatifs (effectiff interrogés insuffisants pour garantir la robustesse des résultats). } \\
\text { Note de lecture : en moyenne entre } 2005 \text { et } 2012,80 \% \text { des professionnels de la culture déclarent des salaires, d'un montant annuel moyen de } 23000 €, 21 \% \\
\text { déclarent des revenus non salariés, d'un montant moyen de } 18300 € \text {, et ill sont } 7 \% \text { à cumuler ces deux natures de revenus d'activité. Au total, } 94 \% \text { des } \\
\text { professionnels de la culture déclarent des revenus directs d'activité strictement positifs, pour un montant annuel moyen de } 23700 € \text {. }\end{array}$} \\
\hline
\end{tabular}

Source : Enquête Revenus fiscaux et sociaux, Insee/DEPS, Ministère de la Culture et de Communication, 2015

les artistes des spectacles ( $8 \%$ ), les professionnels des arts visuels ( $12 \%)$ ou les auteurs littéraires et traducteurs (13\%): il correspond alors vraisemblablement à une combinaison de droits d'auteur (lorsqu'ils sont déclarés en bénéfices non commerciaux) et de salaires (rémunérant par exemple une activité d'enseignement ou une prestation scénique pour un artiste des spectacles).

\section{Un revenu directement lié à l'activité légèrement plus faible dans les professions culturelles}

Tous types d'activités confondues, salariées ou indépendantes, les revenus directement liés à l'activité s'établissent à $23700 €$ en moyenne, un peu moins que pour l'ensemble des actifs en emploi (24000€). Ils se situent entre $16500 €$ et $20500 €$ pour les professionnels des arts visuels ou des métiers d'art, pour les artistes des spectacles et les techniciens des spectacles (assistants opérateurs du son, assistants 
monteurs, techniciens de plateau, costumières...) ainsi que pour les professeurs d'art. Ils sont dans la moyenne, entre 22500 et $26500 €$, pour les auteurs littéraires, les traducteurs et les professionnels de l'archivage, de la conservation et de la documentation. Enfin, ils dépassent en moyenne $30000 €$ pour les journalistes et cadres de l'édition, les cadres artistiques, de programmation et de production des spectacles et pour les architectes (tableau 1).

\section{Un quart des professionnels de la culture perçoivent des revenus de remplacement}

En sus des revenus directement liés à l'activité, une partie des actifs en emploi perçoit des revenus de remplacement (chômage, retraite). Les revenus de remplacement y sont donc à la fois beaucoup plus fréquents et plus élevés que dans l'ensemble de la population en emploi : dans les professions culturelles, $24 \%$ des actifs en perçoivent, pour un montant moyen de $10900 €$ (graphique 1 et tableau 2). Lorsque des revenus de remplacement sont perçus, ils s'élèvent en moyenne à $12000 €$ dans les professions du spectacle et de l'écrit et, à l'inverse, ne dépassent pas $6000 €$ pour les professeurs d'art et les métiers d'art.

Le cumul de revenus directs d'activité et de revenus de remplacement correspond principalement à une combinaison de salaires et d'indemnités de chômage. Cette situation est particulièrement courante dans les métiers du spectacle où près d'un actif sur deux perçoit ces deux types de revenus (61\% chez les artistes, $41 \%$ chez les techniciens et $29 \%$ chez les cadres artistiques, de programmation et de production des spectacles), du fait du dispositif de l'intermittence ${ }^{3}$. Elle est également loin d'être négligeable chez les journalistes et cadres de l'édition (12\%) et chez les professeurs d'art (13\%).

Les architectes et les auteurs littéraires et traducteurs en activité perçoivent plus souvent des pensions de retraite (respectivement $7 \%$ et $11 \%$ ) que la moyenne (5\% dans l'ensemble des professions culturelles et $4 \%$ toutes professions confondues), ces métiers s'exerçant plus souvent que les autres à des âges avancés ${ }^{4}$ (voir tableau A, p. 26).

Le cumul d'indemnités de chômage et de pensions de retraite est pratiquement inexistant, pour les professions culturelles comme pour l'ensemble des actifs en emploi.

\section{Les revenus totaux d'activité des professionnels de la culture dépassent légèrement ceux de l'ensemble des actifs en emploi}

Revenus directement liés à l'activité et revenus de remplacement cumulés, les professionnels de la culture ont perçu $26000 €$ en moyenne dans l'année, au cours de la période, un montant supérieur de $6 \%$ à celui de l'ensemble des actifs en emploi (tableau 3).

Métiers des spectacles, des arts visuels, métiers d'art, professions de l'écrit ou du patrimoine, ou encore architectes ou professeurs d'art : les professions culturelles constituent finalement un ensemble particulièrement hétérogène du point de vue de l'encadrement juridique dont elles font l'objet, des statuts d'emploi dans lesquels elles s'exercent ou encore des compétences et des savoir-faire qu'elles mobilisent. À la diversité des métiers correspond celle des revenus d'activité d'une profession culturelle à l'autre, qui vont de $16700 €$ en moyenne dans les métiers d'art jusqu'à $38000 €$ chez les cadres

3. Marie Gouyon, Frédérique Patureau, Tendances de l'emploi dans le spectacle, Paris, Ministère de la Culture et de la Communication, DEPS, coll. «Culture chiffres », 2014-2, février 2014.

4. M. Gouyon, F. Patureau, Vingt ans d'évolution de l'emploi dans les professions culturelles - 19912011, Paris, Ministère de la Culture et de la Communication, DEPS, coll. « Culture Chiffres », 20146, octobre 2014. 
Tableau 2 - Revenus de remplacement perçus en moyenne chaque année par les actifs en emploi, 2005-2012

\begin{tabular}{|c|c|c|c|c|c|c|}
\hline & \multicolumn{2}{|c|}{$\begin{array}{l}\text { Indemnités } \\
\text { de chômage }\end{array}$} & \multicolumn{2}{|c|}{$\begin{array}{l}\text { Pensions } \\
\text { de retraites }\end{array}$} & \multicolumn{2}{|c|}{$\begin{array}{c}\text { Ensemble } \\
\text { des revenus } \\
\text { de remplacement }\end{array}$} \\
\hline & $\begin{array}{c}\% \\
\text { des } \\
\text { actifs }\end{array}$ & $\begin{array}{l}\text { Montant } \\
\text { moyen } \\
\text { (en euros) }\end{array}$ & $\begin{array}{c}\% \\
\text { des } \\
\text { actifs }\end{array}$ & $\begin{array}{l}\text { Montant } \\
\text { moyen } \\
\text { (en euros) }\end{array}$ & $\begin{array}{c}\% \\
\text { des } \\
\text { actifs* }\end{array}$ & $\begin{array}{c}\text { Montant } \\
\text { moyen } \\
\text { (en euros) }\end{array}$ \\
\hline Professions culturelles & 20 & 10000 & 5 & 14100 & 24 & 10900 \\
\hline $\begin{array}{l}\text { Professions des arts visuels } \\
\text { et des métiers d'art } \\
\text { Professionnels des arts visuels } \\
\text { Métiers d'art }\end{array}$ & $\begin{array}{r}10 \\
10 \\
8\end{array}$ & $\begin{array}{l}6500 \\
6900\end{array}$ & $\begin{array}{l}5 \\
4 \\
6\end{array}$ & $\begin{array}{l}12400 \\
13700\end{array}$ & $\begin{array}{l}15 \\
15 \\
14\end{array}$ & $\begin{array}{l}8500 \\
9100 \\
5100\end{array}$ \\
\hline $\begin{array}{l}\text { Professions du spectacle } \\
\text { Artistes des spectacles } \\
\text { Cadres artistiques, de programmation } \\
\text { et de production des spectacles } \\
\text { Techniciens des spectacles }\end{array}$ & $\begin{array}{l}45 \\
61\end{array}$ & $\begin{array}{l}11900 \\
12300 \\
11600 \\
11500\end{array}$ & $\begin{array}{l}4 \\
5\end{array}$ & 13400 & $\begin{array}{l}48 \\
65\end{array}$ & $\begin{array}{l}12300 \\
12600 \\
12600 \\
11400\end{array}$ \\
\hline $\begin{array}{l}\text { Professions littéraires } \\
\text { Journalistes et cadres de l'édition } \\
\text { Auteurs littéraires et traducteurs }\end{array}$ & $\begin{array}{l}12 \\
12 \\
12\end{array}$ & 8000 & $\begin{array}{r}6 \\
4 \\
11\end{array}$ & 20200 & $\begin{array}{l}18 \\
16 \\
23\end{array}$ & $\begin{array}{l}12200 \\
10900 \\
14500\end{array}$ \\
\hline Architectes & 6 & & 7 & & 12 & 11200 \\
\hline $\begin{array}{l}\text { Professions de l'archivage, } \\
\text { de la conservation } \\
\text { et de la documentation }\end{array}$ & 3 & & 5 & & 7 & \\
\hline Professeurs d'art & 13 & 4200 & 4 & & 17 & 5800 \\
\hline Ensemble des actifs en emploi & 8 & 5000 & 4 & 10500 & 11 & 6800 \\
\hline \multicolumn{7}{|c|}{ 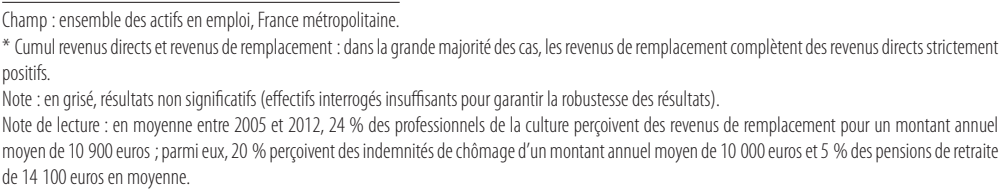 } \\
\hline
\end{tabular}

Source : Enquête Revenus fiscaux et sociaux, Insee/DEPS, Ministère de la Culture et de Communication, 2015

artistiques, de programmation et de production des spectacles. Les professeurs d'art et les professionnels des arts visuels perçoivent en moyenne moins de $21000 €$ annuels pour l'ensemble de leur activité professionnelle. Les auteurs littéraires et traducteurs, les professionnels de l'archivage, de la conservation et de la documentation ainsi que les artistes et les techniciens des spectacles déclarent environ $26000 €$. Enfin, les journalistes et cadres de l'édition perçoivent en moyenne $32100 €$ et les architectes $37200 €$ (tableau 3).

\section{Des revenus d'activité beaucoup plus dispersés dans les professions culturelles que pour l'ensemble des actifs}

Si les professions culturelles divergent nettement les unes des autres en termes de revenu d'activité moyen, on observe de plus pour chacune d'elle une large dispersion des revenus. 
Tableau 3 - Revenus totaux annuels d'activité perçus par les actifs en emploi, 2005-2012

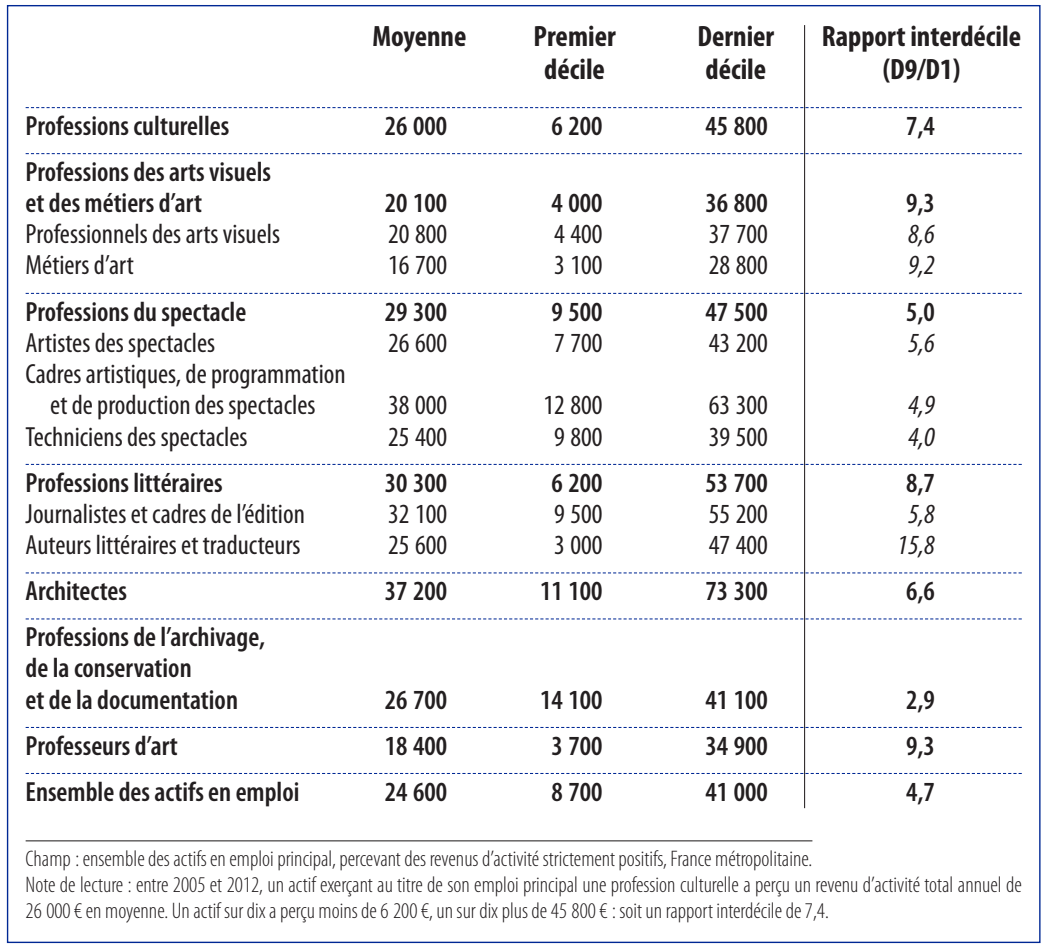

Source: Enquête Revenus fiscaux et sociaux, Insee/DEPS, Ministère de la Culture et de Communication, 2015

En effet, pour l'ensemble des actifs exerçant une profession culturelle, les revenus d'activité les plus bas sont inférieurs à ceux de l'ensemble des actifs, tandis que les plus hauts revenus dépassent largement ceux des mieux rémunérés de leurs concitoyens. Ainsi, les $10 \%$ des professionnels de la culture les moins rémunérés déclarent des revenus annuels d'activité inférieurs à $6200 €$, contre $8700 €$ dans l'ensemble des professions. De l'autre côté du spectre, les $10 \%$ les mieux rémunérés dans la culture déclarent $45800 €$ contre $41000 €$ pour les $10 \%$ les mieux rémunérés toutes professions confondues, d'où un rapport entre les mieux rétribués et les moins bien rémunérés de 7,4 dans la culture, contre 4,7 toutes professions confondues (tableau 3).

Avec un rapport interdécile de près de 16 , la dispersion des revenus d'activité est la plus forte pour les auteurs littéraires et les traducteurs : les $10 \%$ les moins rémunérés déclarent moins de $3000 €$ de revenus annuels d'activité entre 2005 et 2012, tandis que les $10 \%$ les mieux rétribués - les écrivains bénéficiant d'une grande notoriété, de ventes dynamiques et dont les œuvres sont adaptées au cinéma ou à la télévision perçoivent plus de $47400 €$. La dispersion des revenus d'activité est encore assez forte (rapport interdécile d'un peu plus de 9) chez les professionnels des arts visuels et des métiers d'art et chez les professeurs d'art. Elle est plus modérée chez les architectes, les journalistes et cadres de l'édition et dans les professions du spectacle, et surtout dans celles de l'archivage, de la conservation et de la documentation, qui sont souvent exercées par des fonctionnaires, dont les rémunérations sont indexées sur une grille indiciaire de rémunération. 


\section{À caractéristiques sociodémographiques et conditions d'emploi identiques, les professionnels de la culture perçoivent des revenus d'activité inférieurs à ceux des autres actifs}

Les conditions d'emploi et les caractéristiques sociodémographiques ne se répartissent pas de la même façon au sein des professions culturelles et toutes professions confondues $^{5}$. Les professions culturelles relèvent majoritairement de la catégorie sociale des cadres supérieurs ( $57 \%$ des effectifs, contre $17 \%$ dans l'ensemble de la population active en emploi) et sont exercées, plus souvent que les autres, sous statut non salarié. De plus, ces professions sont plus souvent que les autres exercées par des hommes, par des actifs diplômés, d'origine sociale favorisée, résidant en région parisienne (voir tableau A, p. 26). Or les cadres supérieurs et les non-salariés d'une part, les hommes, les titulaires de diplômes de niveau élevé, les actifs issus de milieux sociaux plutôt favorisés, les Franciliens d'autre part, ont des niveaux de revenus supérieurs aux autres. Ces caractéristiques contribuent donc à tirer structurellement les revenus des professionnels de la culture vers le haut.

À l'inverse, par rapport aux autres actifs en emploi, les professionnels de la culture ont des temps de travail en moyenne plus courts, caractéristique qui va de pair avec un revenu d'activité moindre, ce qui tire donc la moyenne des revenus des professionnels de la culture vers le bas.

Pour comparer convenablement les revenus des professionnels de la culture à ceux des autres actifs, il convient donc de tenir compte de ces effets de structure. Ainsi, alors que les revenus d'activité totaux des professionnels de la culture sont supérieurs de $6 \%$ à ceux de l'ensemble des actifs, si l'on prend en compte ces différentes caractéristiques en cherchant à neutraliser leur effet, le surcroît des revenus d'activité des professionnels de la culture disparaît et devient même négatif. À caractéristiques sociodémographiques et conditions d'emploi identiques, un professionnel de la culture perçoit en effet un revenu d'activité inférieur en moyenne de $26 \%$ à celui d'un actif exerçant une autre profession (tableau 4).

\section{Dans les professions culturelles, les femmes perçoivent des revenus d'activité inférieurs en moyenne de $19 \%$ à ceux des hommes}

Toutes professions confondues, les femmes tirent en moyenne de leur activité professionnelle des revenus très inférieurs à ceux des hommes ${ }^{6}$ : elles ont perçu $20300 €$ en moyenne de revenus totaux d'activité entre 2005 et 2012, soit $29 \%$ de moins que les hommes (28 $400 €$ ) (tableau 5). Ce constat est confirmé toutes choses égales par ailleurs : à mêmes conditions d'emploi que les hommes (notamment en termes de temps de travail, moindre en moyenne pour les femmes) et autres caractéristiques sociodémographiques identiques, les femmes ont un revenu d'activité inférieur en moyenne de $28 \%$ (tableau 4).

Les professionnelles de la culture ont perçu, entre 2005 et 2012, en moyenne $22900 €$ de revenus d'activité, soit $19 \%$ de moins que leurs confrères masculins (28 $300 €$ ). L'écart en défaveur des femmes est assez faible dans les professions des arts visuels, de l'archivage, de la conservation et de la documentation (exercées pour partie par des fonctionnaires, dont les salaires reposent sur une grille indiciaire) et chez les techniciens et cadres artistiques, de programmation et de production des spectacles (où les temps de travail différencient moins qu'ailleurs les hommes et les

5. M. Gouyon, F. Patureau, Vingt ans d'évolution de l'emploi dans les professions culturelles - 19912011, op. cit.

6. Sophie PonthiEux, "L'inégalité des revenus d'activité et les niveaux de vie des femmes et des hommes - Une comparaison entre cinq pays de I'Union européenne ", Insee, "Économie et Statistique », n 469-470, 2014. 
Tableau 4 - Déterminants des revenus d'activité de l'ensemble des actifs en emploi, des professionnels de la culture, et des actifs exerçant une profession non culturelle, 2005-2012

\begin{tabular}{|c|c|c|c|c|}
\hline \multirow[b]{2}{*}{ Variable explicative } & \multicolumn{3}{|c|}{$\begin{array}{l}\text { Effet marginal sur le revenu d'activité total } \\
\text { (en \%) en moyenne par rapport à la modalité de référence }\end{array}$} & \multirow{2}{*}{$\begin{array}{c}\text { Test } \\
\text { de } \\
\text { différence }\end{array}$} \\
\hline & Ensemble & $\begin{array}{l}\text { Professions } \\
\text { culturelles }\end{array}$ & $\begin{array}{c}\text { Professions } \\
\text { non culturelles }\end{array}$ & \\
\hline $\begin{array}{l}\text { Domaine professionnel } \\
\text { Profession culturelle } \\
\text { Profession non culturelle }\end{array}$ & $\begin{array}{r}-26 \\
\text { ref }\end{array}$ & & & \\
\hline $\begin{array}{l}\text { Catégorie sociale } \\
\text { Cadres et professions intellectuelles supérieures* } \\
\text { Autre catégorie socioprofessionnelle }\end{array}$ & $\begin{array}{r}+56 \\
r e f\end{array}$ & $\begin{array}{c}+25 \\
\text { ref }\end{array}$ & $\begin{array}{r}+58 \\
r e f\end{array}$ & +++ \\
\hline $\begin{array}{l}\text { Statut d'activité } \\
\text { Salarié } \\
\text { Non-salarié }\end{array}$ & $\begin{array}{r}+98 \\
r e f\end{array}$ & $\begin{array}{r}+140 \\
\text { ref }\end{array}$ & $\begin{array}{r}+96 \\
r e f\end{array}$ & +++ \\
\hline $\begin{array}{l}\text { Temps de travail hebdomadaire } \\
\text { Moins de } 20 \text { heures } \\
\text { De } 20 \text { à } 31 \text { heures } \\
\text { De } 32 \text { à } 37 \text { heures } \\
\text { De } 38 \text { à } 41 \text { heures } \\
42 \text { heures ou + }\end{array}$ & $\begin{array}{r}-76 \\
-15 \\
r e f \\
+12 \\
+15\end{array}$ & $\begin{array}{r}-92 \\
-30 \\
r e f \\
+10 \mathrm{~ns} \\
+26\end{array}$ & $\begin{array}{r}-76 \\
-14 \\
r e f \\
+12 \\
+14\end{array}$ & $\begin{array}{c}+ \\
++ \\
\text { ns } \\
\text { ns }\end{array}$ \\
\hline $\begin{array}{l}\text { Sexe } \\
\text { Homme } \\
\text { Femme }\end{array}$ & $\begin{array}{r}r e f \\
-28\end{array}$ & $\begin{array}{r}r e f \\
-40\end{array}$ & $\begin{array}{r}r e f \\
-28\end{array}$ & + \\
\hline $\begin{array}{l}\text { Âge } \\
40 \text { ans ou }+ \text { ref }\end{array}$ & $\begin{array}{r}-43 \\
r e f\end{array}$ & $\begin{array}{c}-21 \\
\text { ref }\end{array}$ & -44 & +++ \\
\hline $\begin{array}{l}\text { Milieu social d'origine } \\
\text { Père cadre (supérieur ou intermédiaire) } \\
\text { Père d'une autre catégorie sociale }\end{array}$ & $\begin{array}{r}\text { ref } \\
+33\end{array}$ & $\begin{array}{r}r e f \\
+20\end{array}$ & $\begin{array}{r}\text { ref } \\
+33\end{array}$ & + \\
\hline $\begin{array}{l}\text { Niveau de diplôme } \\
\mathrm{Bac}+2 \text { ou moins } \\
\mathrm{Bac}+3 \text { ou plus }\end{array}$ & $\begin{array}{c}+2 \\
\text { ref }\end{array}$ & $\begin{array}{l}+2 \mathrm{~ns} \\
\text { ref }\end{array}$ & $\begin{array}{l}+2 \\
\text { ref }\end{array}$ & ns \\
\hline $\begin{array}{l}\text { Lieu de résidence } \\
\text { Commune francilienne } \\
\text { Autre commune rurale } \\
\text { Autre commune urbaine }\end{array}$ & $\begin{array}{r}+26 \\
r e f \\
+8\end{array}$ & $\begin{array}{r}+35 \\
\text { ref } \\
+10 \mathrm{~ns}\end{array}$ & $\begin{array}{r}+26 \\
\text { ref } \\
+8\end{array}$ & ns \\
\hline $\begin{array}{l}\text { Statut vis-à-vis du logement } \\
\text { Propriétaire } \\
\text { Locataire } \\
\text { Logé à titre gratuit }\end{array}$ & $\begin{array}{r}\text { ref } \\
-13 \\
-1 \mathrm{~ns}\end{array}$ & $\begin{array}{r}r e f \\
-19 \\
-22 \mathrm{~ns}\end{array}$ & $\begin{array}{r}\text { ref } \\
-12 \\
-1 \mathrm{~ns}\end{array}$ & ns \\
\hline $\begin{array}{l}\text { Vie de famille } \\
\text { En couple avec enfant(s) } \\
\text { En couple sans enfant } \\
\text { Famille monoparentale } \\
\text { Seul sans enfant }\end{array}$ & $\begin{array}{r}+9 \\
r e f \\
-97 \\
-2\end{array}$ & $\begin{array}{r}+8 \mathrm{~ns} \\
\text { ref } \\
-64 \\
-4 \mathrm{~ns}\end{array}$ & $\begin{array}{r}+10 \\
\text { ref } \\
-97 \\
-2\end{array}$ & $\begin{array}{c}\text { ns } \\
++ \\
\text { ns }\end{array}$ \\
\hline 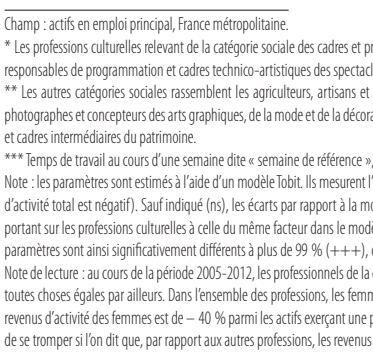 & 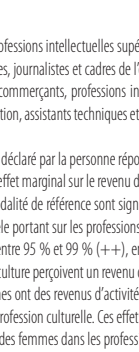 & 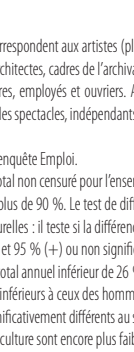 & 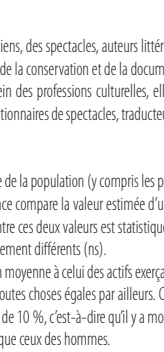 & $\begin{array}{l}\text { res), professeurs d'art, } \\
\text { tatation. } \\
\text { s sont composées des } \\
\text { s, sous-bibliothécaires } \\
\text { sonnes dont le revenu } \\
\text { paramètre du modèle } \\
\text { nent significative ; ces } \\
\text { tune autre profession, } \\
\text { effet marginal sur les } \\
\text { sd'une chance sur dix }\end{array}$ \\
\hline
\end{tabular}


Tableau 5 - Revenus d'activité annuels moyens des hommes et des femmes, 2005-2012

\begin{tabular}{|c|c|c|c|}
\hline & Hommes & Femmes & $\begin{array}{c}\text { Écart } \\
\text { femmes/hommes } \\
(e n \%)\end{array}$ \\
\hline Professions culturelles & 28300 & 22900 & -19 \\
\hline Professions des arts visuels et des métiers d'art & 21300 & 18500 & -13 \\
\hline Professionnels des arts visuels & 21600 & 19700 & -9 \\
\hline Métiers d'art & 19900 & 12000 & -40 \\
\hline Professions du spectacle & 30200 & 27500 & -9 \\
\hline Artistes des spectacles & 28300 & 23000 & -19 \\
\hline Cadres artistiques, de programmation & & & \\
\hline et de production des spectacles & 39500 & 35400 & -10 \\
\hline Techniciens des spectacles & 25600 & 24600 & -4 \\
\hline Professions littéraires & 35100 & 25500 & -27 \\
\hline Journalistes et cadres de l'édition & 37100 & 27200 & -27 \\
\hline Auteurs littéraires et traducteurs & 30000 & 20900 & -30 \\
\hline Architectes & 40600 & 29800 & -27 \\
\hline $\begin{array}{l}\text { Professions de l'archivage, de la conservation } \\
\text { et de la documentation }\end{array}$ & 29100 & 25900 & -11 \\
\hline Professeurs d'art & 20200 & 17000 & -16 \\
\hline Ensemble des actifs en emploi & 28400 & 20300 & -29 \\
\hline
\end{tabular}

Source : Enquête Revenus fiscaux et sociaux, Insee/DEPs, Ministère de la Culture et de Communication, 2015

femmes). II dépasse en revanche $25 \%$ dans la profession d'architecte et les métiers littéraires et atteint même $40 \%$ dans les métiers d'art.

D'une façon générale, les caractéristiques d'emploi et sociodémographiques des femmes et des hommes sont assez différentes. Les femmes sont, par exemple, plus diplômées que les hommes, mais ont des temps de travail plus courts, des caractéristiques qui sont plus ou moins accentuées dans les professions culturelles. Si on neutralise statistiquement ces caractéristiques, les professionnelles de la culture ont alors des revenus d'activité inférieurs, en moyenne, de $40 \%$ à ceux de leurs collègues masculins (tableau 4). Pour les professions culturelles, la prise en compte des effets de structure n'atténue pas les différences de revenus entre les femmes et les hommes, au contraire elle les creuse plus encore.

Autrement dit, les différents éléments qui caractérisent habituellement les individus d'un point de vue social et familial n'expliquent pas l'écart de revenu d'activité entre les femmes et les hommes. D'autres facteurs, que la source statistique utilisée ne permet pas d'observer, influent de façon déterminante : il peut s'agir de la spécialité du diplôme, de son prestige, de l'étendue et de la qualité des réseaux amicaux, familiaux et professionnels de la personne, par exemple ou encore, pour les femmes auteurs, de la façon dont sont diffusées leurs œuvres ${ }^{7}$.

7. Voir M. Gouyon, les Femmes dans la création audiovisuelle et de spectacle vivant, Paris, Ministère de la Culture et de la Communication, DEPS, coll. «Culture chiffres », 2014-4. 


\section{Du revenu d'activité du professionnel de la culture au revenu disponible de son ménage}

Du fait de la composition du ménage (en couple, avec un conjoint actif ou non, présence ou non d'enfants, etc.) et de l'histoire familiale (transmission de patrimoine par exemple), d'autres sources de revenus peuvent compléter le revenu d'activité: revenus d'activité du conjoint et des autres membres du ménage, revenus d'origine sociale (prestations familiales, allocations logement, minima sociaux), financière (revenus des livrets d'épargne, dividendes, plus-values financières), foncière (loyers perçus) ou autre (prime pour l'emploi notamment), et ne pas être associés à un individu mais versés au ménage dans son ensemble (voir "Définitions», p. 23). La prise en compte de l'ensemble de ces revenus et de la composition du ménage permet d'analyser le revenu disponible du ménage dans lequel vit le professionnel de la culture et, par suite, son niveau de vie.

\section{Les revenus d'activité du conjoint ou d'autres membres du ménage constituent un renfort important pour les professions culturelles les moins rémunératrices}

Les actifs qui exercent une profession culturelle vivent un peu moins souvent en couple que les autres mais, lorsque c'est le cas, il est nettement plus fréquent qu'ils partagent leur vie avec un(e) cadre intermédiaire ou supérieur(e). De plus, les professions culturelles sont moins rémunératrices que les autres « toutes choses égales par ailleurs » (tableau 4). Les revenus d'activité sont complétés, pour plus des deux tiers des professionnels de la culture, par des revenus apportés au ménage par un(e) conjoint(e) actif(ve) et/ou un autre de ses membres, par exemple un étudiant vivant chez ses parents et travaillant de façon rémunérée l'été ou quelques heures chaque semaine parallèlement à ses études. Ce revenu d'activité que le conjoint et/ou un autre actif apporte au ménage est en moyenne plus élevé dans les ménages des professionnels de la culture (30 $200 €$ ) que dans l'ensemble des ménages composés de plusieurs actifs (26000 $€$ ), et, pour les professionnels de la culture, les revenus d'activité complémentaires sont nettement supérieurs à leurs propres revenus (16\% de plus) (graphique 2, tableau 6).

Cet écart est particulièrement fort dans les ménages des professionnels des arts visuels, des auteurs littéraires et traducteurs et des professeurs d'art, où le revenu du conjoint est vraisemblablement un soutien, parfois indispensable, à la poursuite de l'activité artistique. L'écart est également considérable dans les ménages des professionnels de l'archivage, de la conservation et de la documentation et s'explique davantage par le fait que ces professions sont très majoritairement exercées par des femmes alors que les revenus d'activité complémentaires sont majoritairement apportés par des hommes - dont les revenus d'activité sont, de façon générale, plus élevés que ceux des femmes ( $+29 \%$ pour l'ensemble des actifs).

À l'inverse, l'écart entre les revenus d'activité des professionnels de la culture et ceux des autres membres de leur ménage est réduit, voire inversé, pour les professions culturelles les mieux rémunérées, telles que les journalistes et cadres de l'édition, les architectes et les cadres artistiques, de programmation et de production des spectacles (tableau 6).

\section{Les revenus d'activité des ménages des professionnels de la culture sont supérieurs à ceux de l'ensemble des ménages d'actifs (+ de $6 \%$ )}

En sommant les revenus d'activité des personnes qui les composent, les ménages des professionnels de la culture perçoivent des revenus annuels moyens d'activité de $46300 €$ au cours de la période 2005-2012. Ils sont de $6 \%$ plus élevés que ceux de l'ensemble des ménages d'actifs en emploi (tableau 6). 


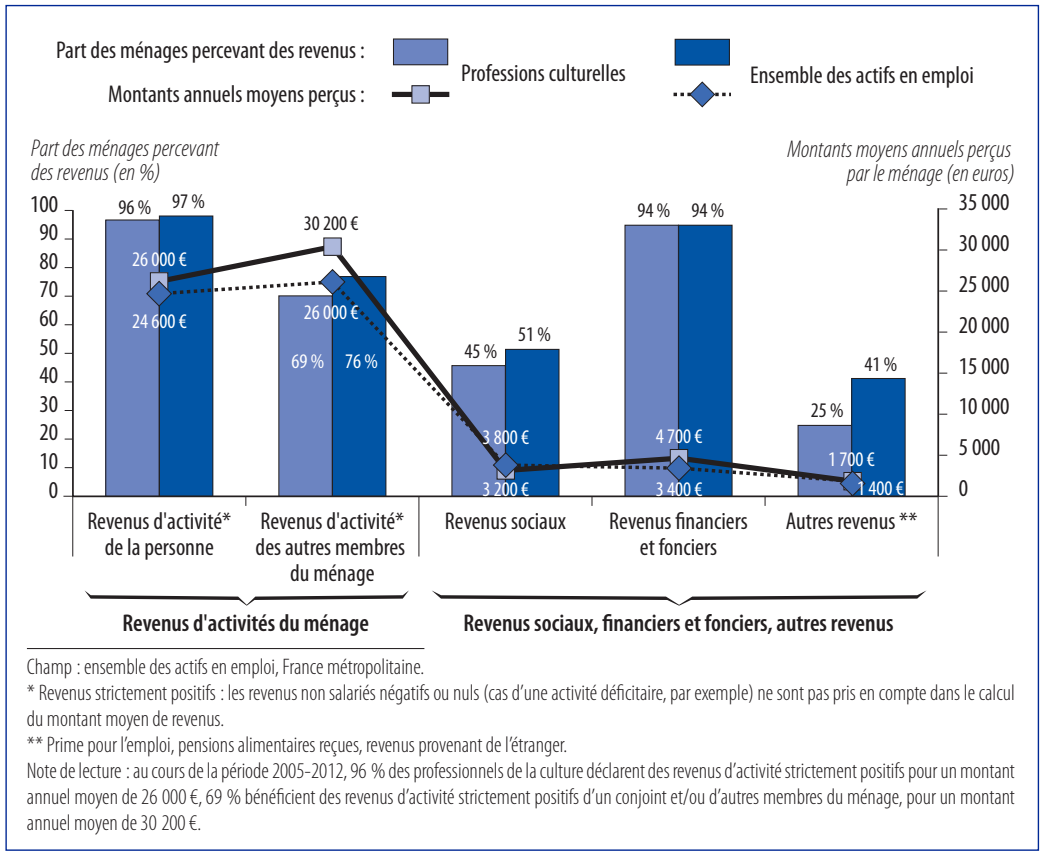

Source : Enquête Revenus fiscaux et sociaux, Insee/DEPs, Ministère de la Culture et de la Communication, 2015

Les écarts importants observés entre les revenus d'activité propres des professionnels de la culture d'une profession culturelle à l'autre s'atténuent nettement une fois pris en compte les revenus d'activité du conjoint des autres actifs du ménage, à l'exception des ménages des métiers d'art, dont le revenu moyen d'activité demeure très faible (33 $400 €$ ), bien en deçà de la moyenne nationale (43 $700 €)$.

Les ménages des professionnels des arts visuels, des professeurs d'art et des techniciens des spectacles déclarent ainsi des revenus d'activité compris, en moyenne, entre $40000 €$ et la moyenne de l'ensemble des professions. Les ménages des artistes des spectacles, des auteurs littéraires et des traducteurs, ainsi que des professionnels de l'archivage, de la conservation et de la documentation se situent au-delà, avec un revenu d'activité global compris entre la moyenne nationale et $50000 €$. Enfin, les ménages des architectes, des journalistes et cadres de l'édition et des cadres artistiques, de production et de programmation des spectacles déclarent en moyenne plus de $50000 €$ de revenus d'activité.

\section{Moins de ménages bénéficiaires de prestations sociales, pour un montant en moyenne moindre que dans l'ensemble des ménages d'actifs en emploi}

Les prestations sociales sont composées principalement de prestations familiales, mais aussi de prestations logement et de minima sociaux. Elles sont conditionnées notamment par le niveau de ressources du ménage, par sa composition (le nombre d'enfants à charge par exemple) et par son lieu de résidence.

Les ménages des professionnels de la culture ont moins souvent que les autres des enfants à charge et, lorsqu'ils en ont, c'est en moins grand nombre (voir tableau A, 
Tableau 6 - Revenus annuels d'activité perçus par les ménages d'actifs en emploi, 2005-2012

\begin{tabular}{|c|c|c|c|c|c|c|}
\hline & \multicolumn{2}{|c|}{$\begin{array}{l}\text { Revenus d'activité* } \\
\text { de la personne }\end{array}$} & \multicolumn{2}{|c|}{$\begin{array}{l}\text { Revenus d'activité* } \\
\text { des autres membres } \\
\text { du ménage }\end{array}$} & \multicolumn{2}{|c|}{$\begin{array}{l}\text { Ensemble des revenus } \\
\text { d'activité }^{*} \text { du ménage }\end{array}$} \\
\hline & $\begin{array}{c}\text { \% des } \\
\text { ménages } \\
\text { concernés }\end{array}$ & $\begin{array}{l}\text { Montant } \\
\text { annuel } \\
\text { moyen } \\
\text { (en } € \text { ) }\end{array}$ & $\begin{array}{c}\text { \% des } \\
\text { ménages } \\
\text { concernés }\end{array}$ & $\begin{array}{l}\text { Montant } \\
\text { annuel } \\
\text { moyen } \\
\text { (en } €)\end{array}$ & $\begin{array}{c}\text { \% des } \\
\text { ménages } \\
\text { concernés }\end{array}$ & $\begin{array}{c}\text { Montant } \\
\text { annuel } \\
\text { moyen } \\
\text { (en } € \text { ) }\end{array}$ \\
\hline Professions culturelles & 96 & 26000 & 69 & 30200 & 99 & 46300 \\
\hline $\begin{array}{l}\text { Professions des arts visuels } \\
\text { et des métiers d'art } \\
\text { Professionnels des arts visuels } \\
\text { Métiers d'art }\end{array}$ & $\begin{array}{l}93 \\
93 \\
94\end{array}$ & $\begin{array}{l}20100 \\
20800 \\
16700\end{array}$ & $\begin{array}{l}70 \\
69 \\
75\end{array}$ & $\begin{array}{l}27900 \\
29000 \\
22900\end{array}$ & $\begin{array}{l}98 \\
98 \\
98\end{array}$ & $\begin{array}{l}39000 \\
40000 \\
33400\end{array}$ \\
\hline $\begin{array}{l}\text { Professions du spectacle } \\
\text { Artistes des spectacles } \\
\text { Cadres artistiques, de programmation } \\
\text { et de production des spectacles } \\
\text { Techniciens des spectacles }\end{array}$ & $\begin{array}{l}97 \\
98 \\
\\
94 \\
98\end{array}$ & $\begin{array}{l}29300 \\
26600 \\
38000 \\
25400\end{array}$ & $\begin{array}{l}68 \\
68\end{array}$ & $\begin{array}{l}29100 \\
30600 \\
30100 \\
26600\end{array}$ & $\begin{array}{l}99 \\
99\end{array}$ & $\begin{array}{l}48700 \\
47100 \\
\\
57500 \\
43200\end{array}$ \\
\hline $\begin{array}{l}\text { Professions littéraires } \\
\text { Journalistes et cadres de l'édition } \\
\text { Auteurs littéraires et traducteurs }\end{array}$ & $\begin{array}{l}96 \\
98 \\
90\end{array}$ & $\begin{array}{l}30300 \\
32100 \\
25600\end{array}$ & $\begin{array}{l}68 \\
68 \\
67\end{array}$ & $\begin{array}{l}35300 \\
34500 \\
37200\end{array}$ & $\begin{array}{l}99 \\
100 \\
97\end{array}$ & $\begin{array}{l}53700 \\
55300 \\
49700\end{array}$ \\
\hline Architectes & 97 & 37200 & 74 & 30100 & 100 & 58200 \\
\hline $\begin{array}{l}\text { Professions de l'archivage, } \\
\text { de la conservation } \\
\text { et de la documentation }\end{array}$ & 100 & 26700 & 64 & 37600 & 100 & 50600 \\
\hline Professeurs d'art & 98 & 18400 & 70 & 31100 & 99 & 40200 \\
\hline Ensemble des actifs en emploi & 97 & 24600 & 76 & 26000 & 99 & 43700 \\
\hline $\begin{array}{l}\text { Champ : ensemble des actifs en emploi principal, } \\
\text { * Revenus strictement positifs : dans le calcul du m } \\
\text { activité déficitaire, par exemple). } \\
\text { Note de lecture en moyenne, entre } 2005 \text { et } 2012, \\
\text { moyenne dans l'année), } 69 \% \text { déclarent des revenu } \\
30200 € \text { €). Au total, } 99 \% \text { bénéficient, au sein de le }\end{array}$ & $\begin{array}{l}\text { percevant des rev } \\
\text { montant moyen } \\
\text { 2,96\% des profes } \\
\text { enus d'activité stric } \\
\text { leur ménage, de r }\end{array}$ & $\begin{array}{l}\text { enus d'activité } \\
\text { le revenus, nes } \\
\text { sionnels de lac } \\
\text { ement positifs } \\
\text { evenus d'activit }\end{array}$ & $\begin{array}{l}\text { ment positifs, } \mathrm{Fr} \\
\text { as pris en comp } \\
\text { déclarent des re } \\
\text { onjoint et/ou d } \\
\text { tement positifs, }\end{array}$ & $\begin{array}{l}\text { nce métropoli } \\
\text { les revenus n } \\
\text { enus d'activite } \\
\text { Itres membre } \\
\text { our un monta }\end{array}$ & $\begin{array}{l}\text { lariés négatifis } \\
\text { ement positifs } \\
\text { énage (d'un r } \\
\text { nuel moyen de }\end{array}$ & $\begin{array}{l}\text { nuls (cas d'une } \\
\text { ur } 26000 € \text { en } \\
\text { tant moyen de } \\
300 € \text {. }\end{array}$ \\
\hline
\end{tabular}

Source: Enquête Revenus fiscaux et Sociaux, Insee/DEPS, Ministère de la Culture et de Communication, 2015

p. 26). De ce fait, leurs ménages perçoivent moins fréquemment des prestations sociales : $45 \%$ en sont bénéficiaires contre $51 \%$ toutes professions confondues (tableau 7). Le montant annuel moyen des prestations perçues au cours de la période 2005-2012 est de $3200 €$, inférieur de $19 \%$ à la moyenne des ménages d'actifs en emploi (3 $800 €)$.

Au sein des professions culturelles, les prestations sociales sont plus répandues parmi les ménages des professionnels des arts visuels et des métiers d'art et surtout des professeurs d'art - c'est-à-dire les métiers culturels dont les revenus d'activité sont les plus faibles. Elles le sont beaucoup moins dans les ménages des professionnels de l'écrit, des spectacles et également de l'archivage, de la conservation et de la documentation qui sont plus fréquemment que les autres sans enfant à charge.

Parmi les actifs en emploi, $6 \%$ vivent dans un ménage bénéficiaire de minima sociaux (RMI jusqu'en 2008, RSA ensuite), $7 \%$ parmi les professionnels de la culture (tableau 7). Le montant de prestations associé est, en moyenne, sensiblement le même (environ $3500 €$ ). Comme l'ensemble des prestations sociales, les minima sociaux 
Tableau 7 - Revenus hors activité perçus par les ménages des actifs emploi, 2005-2012

\begin{tabular}{|c|c|c|c|c|}
\hline & \multicolumn{2}{|c|}{ Revenus sociaux } & \multicolumn{2}{|c|}{$\begin{array}{l}\text { Parmi les revenus sociaux : } \\
\text { minima sociaux }\end{array}$} \\
\hline & $\begin{array}{l}\% \text { des ménages } \\
\text { concernés }\end{array}$ & $\begin{array}{c}\text { Montant } \\
\text { annuel moyen } \\
\text { (en } €)\end{array}$ & $\begin{array}{l}\text { \% des ménages } \\
\text { concernés }\end{array}$ & $\begin{array}{l}\text { Montant } \\
\text { annuel moyen } \\
\quad(e n €)\end{array}$ \\
\hline Professions culturelles & 45 & 3200 & 7 & 3500 \\
\hline $\begin{array}{l}\text { Professions des arts visuels et des métiers d'art } \\
\text { Professionnels des arts visuels } \\
\text { Métiers d'art }\end{array}$ & $\begin{array}{l}48 \\
49 \\
47\end{array}$ & $\begin{array}{l}3400 \\
3300 \\
3700\end{array}$ & $\begin{array}{l}9 \\
8 \\
11\end{array}$ & 3500 \\
\hline $\begin{array}{l}\text { Professions du spectacle } \\
\text { Artistes des spectacles } \\
\text { Cadres artistiques, de programmation } \\
\text { et de production des spectacles } \\
\text { Techniciens des spectacles }\end{array}$ & $\begin{array}{l}41 \\
43 \\
41 \\
39\end{array}$ & $\begin{array}{l}3100 \\
3400 \\
2500 \\
3200\end{array}$ & $\begin{array}{l}7 \\
11 \\
2 \\
6\end{array}$ & 3300 \\
\hline $\begin{array}{l}\text { Professions littéraires } \\
\text { Journalistes et cadres de l'édition } \\
\text { Auteurs littéraires et traducteurs }\end{array}$ & $\begin{array}{l}45 \\
44 \\
46\end{array}$ & $\begin{array}{l}3000 \\
2700 \\
3700\end{array}$ & $\begin{array}{l}3 \\
2 \\
6\end{array}$ & \\
\hline Architectes & 45 & 3000 & 2 & \\
\hline $\begin{array}{l}\text { Professions de l'archivage, de la conservation } \\
\text { et de la documentation }\end{array}$ & 38 & 3200 & 3 & \\
\hline Professeurs d'art & 53 & 3400 & 9 & \\
\hline Ensemble des actifs en emploi & 51 & 3800 & 6 & 3600 \\
\hline $\begin{array}{l}\text { Champ : ensemble des actifs en emploi, France métropolitaine. } \\
\text { * Prime pour l'emploi, pensions alimentaires reçues, revenus proven } \\
\text { Note : en grisé : résultats non significatiffs (les effectifs interrogés so }\end{array}$ & $\begin{array}{l}\text { nt de l'́tranger. } \\
\text { insuffisants). }\end{array}$ & & & \\
\hline
\end{tabular}

sont plus fréquemment perçus par les ménages d'artistes ou de professionnels proches des métiers artistiques stricto sensu: professionnels des arts visuels, métiers d'art, professeurs d'art et artistes des spectacles.

\section{Des revenus fonciers et financiers plus élevés pour les professionnels de la culture}

Les revenus du patrimoine correspondent aux intérêts de l'épargne défiscalisée, aux dividendes, aux intérêts des valeurs mobilières et placements financiers, et aux plus-values mobilières et aux loyers perçus. Ils sont aussi répandus dans les ménages des professionnels de la culture que dans l'ensemble des ménages d'actifs (94\%) mais sont très nettement supérieurs, en moyenne, chez les premiers (4 $700 €$ chaque année, pour la période 2005-2012) que chez les seconds (3 $400 €$ ) (tableau 7). Il s'agit, pour une très large majorité, de revenus issus de l'épargne exonérée d'impôt sur le revenu, tels que livret $A$, assurance vie, plans épargne logement, plans d'épargne populaire, etc.

Selon la profession culturelle exercée, la part des actifs vivant dans un ménage qui perçoit des revenus financiers et fonciers est sensiblement la même, oscillant entre $91 \%$ et $98 \%$. En revanche, les montants associés sont très variables. Les revenus fonciers et financiers s'établissent, en moyenne, en deçà de $4000 €$ dans les ménages des professionnels des arts visuels et métiers d'art, des artistes et des techniciens des 


\section{Revenus financiers et fonciers}

\begin{tabular}{cc}
\hline $\begin{array}{c}\text { des ménages } \\
\text { concernés }\end{array}$ & $\begin{array}{c}\text { Montant } \\
\text { annuel moyen }\end{array}$
\end{tabular}

\section{\begin{tabular}{cc}
\multicolumn{2}{c}{ Autres revenus* } \\
\hline $\begin{array}{c}\text { \% des ménages } \\
\text { concernés }\end{array}$ & $\begin{array}{c}\text { Montant } \\
\text { annuel moyen }\end{array}$
\end{tabular}}

\section{Ensemble des revenus hors activité du ménage}

$\%$ des ménages Montant concernés annuel moyen

\begin{tabular}{|c|c|c|c|c|c|}
\hline & $(e n €)$ & & $(e n €)$ & & $(e n €)$ \\
\hline 94 & 4700 & 25 & 1700 & 96 & 6800 \\
\hline 92 & 3400 & 32 & 1600 & 96 & 5800 \\
\hline 93 & 3700 & 30 & 1600 & 96 & 5900 \\
\hline 91 & 3400 & 44 & 1300 & 97 & 5600 \\
\hline 94 & 4300 & 22 & 1800 & 96 & 6100 \\
\hline 94 & 3300 & 21 & 2000 & 97 & 5200 \\
\hline 95 & 8400 & 21 & 1900 & 96 & 10000 \\
\hline 94 & 2000 & 25 & 1400 & 95 & 3800 \\
\hline 95 & 5200 & 20 & 2200 & 95 & 7400 \\
\hline 95 & 5500 & 17 & 2300 & 95 & 7600 \\
\hline 94 & 4500 & 25 & 2000 & 95 & 7100 \\
\hline 98 & 10600 & 17 & 1700 & 96 & 12800 \\
\hline 96 & 3100 & 20 & 1500 & 97 & 4900 \\
\hline 93 & 4200 & 23 & 1900 & 98 & 6400 \\
\hline 94 & 3400 & 41 & 1400 & 97 & 6000 \\
\hline
\end{tabular}

Note de lecture : en moyenne entre 2005 et 2012, $45 \%$ des professionnels de la culture vivent dans un ménage qui perçoit des revenus sociaux d'un montant moyen de $3200 €$ dans l'année ; $7 \%$ dans un ménage bénéficiaire de minima sociaux (3 500 € en moyenne) ; $94 \%$ perçoivent des revenus financiers et fonciers au titre de leur ménage d’un montant moyen de $4700 € ; 25 \%$ perçoivent d'autres types de revenus, comme la prime pour l'emploi (de $1700 €$ en moyenne). Au total, $96 \%$ bénéficient de revenus complémentaires aux revenus d'activité, pour un montant annuel moyen de $6800 €$.

spectacles, des professionnels de l'archivage, de la conservation et de la documentation et des professeurs d'art. Ils dépassent $5000 €$ dans les ménages des professionnels de l'écrit, des cadres artistiques, de programmation et de production des spectacles et des architectes. Ceux-là se distinguent par une origine sociale plutôt favorisée: ils sont près de $60 \%$ à avoir un père cadre supérieur ou intermédiaire (voir tableau $A$, p. 26) : on peut faire l'hypothèse que, par leur origine familiale, ces actifs disposent plus souvent que la moyenne d'un patrimoine financier ou immobilier, ce qui explique que les revenus financiers et fonciers de leur ménage sont nettement supérieurs à ceux des autres.

\section{Un quart des ménages des professionnels de la culture perçoivent des revenus tels que prime pour l'emploi ou pensions alimentaires, pour un montant moyen annuel de 1700 euros}

D'autres revenus peuvent enfin compléter les moyens dont le ménage dispose pour vivre : il s'agit essentiellement de la prime pour l'emploi, mais aussi des pensions alimentaires qu'il reçoit et, plus marginalement, de revenus provenant de l'étranger (voir «Définitions», p. 23). Un quart des ménages des professionnels de la culture perçoivent des revenus de cette nature (proportion variant de $17 \%$ dans les ménages d'architectes à $32 \%$ dans les ménages des professionnels des arts visuels et des 
métiers d'art), contre $41 \%$ de l'ensemble des ménages d'actifs en emploi (tableau 7). Les montants sont en moyenne un peu plus élevés pour les professionnels de la culture (1 $700 €$ chaque année) que pour l'ensemble des actifs (1 $400 €$ ).

\section{Presque tous les ménages d'actifs perçoivent des revenus hors activité, pour un montant moyen plus élevé dans les ménages des professionnels de la culture}

Au total, presque tous les actifs en emploi, qu'ils exercent une profession culturelle ou non, perçoivent des revenus dissociés de l'activité professionnelle: prestations sociales, revenus financiers et fonciers ou, plus marginalement, revenus d'autre nature comme la prime pour l'emploi. D'un montant annuel moyen de $6800 €$ de 2005 à 2012 , ces autres revenus sont, dans les ménages des professionnels de la culture, supérieurs de $13 \%$ à ceux de l'ensemble des ménages d'actifs en emploi (6 $000 €$ ) (tableau 7).

Ces montants sont compris entre $4000 €$ et $6000 €$ dans les ménages des professionnels des arts visuels et métiers d'art, des artistes et des techniciens des spectacles, des professeurs d'art et des professionnels de l'archivage, de la conservation et de la documentation, et s'appuient pour une large part sur les prestations sociales.

Ils s'établissent à un peu plus de $7000 €$ en moyenne dans l'année dans les ménages des professionnels de l'écrit, à $10000 €$ pour les cadres artistiques, de programmation et de production des spectacles et atteignent $13000 €$ pour les ménages d'architectes. Ils proviennent alors, essentiellement, de revenus financiers et fonciers.

\section{Un revenu disponible en moyenne proche de celui de l'ensemble des ménages d'actifs en emploi}

À l'ensemble des revenus sont soustraits les impôts (impôt sur le revenu, taxe d'habitation sur la résidence principale) et les éventuelles pensions alimentaires que le ménage verse, pour parvenir à la mesure du revenu disponible du ménage. Dans les ménages des professionnels de la culture, celui-ci s'établit en moyenne à $47300 €$ par an au cours de la période $2005-2012$, soit $4 \%$ de plus que dans l'ensemble des ménages d'actifs en emploi (graphique 3$)^{8}$.

\section{Du revenu disponible du ménage au niveau de vie du professionnel de la culture}

Le niveau de vie se définit comme le revenu disponible du ménage divisé par le nombre d'unités de consommation. Il est par définition le même pour toutes les personnes composant ce ménage.

\section{Les professionnels de la culture ont un niveau de vie moyen supérieur de $11 \%$ à celui de l'ensemble des actifs en emploi}

De 2005 à 2012, les professionnels de la culture ont globalement un niveau de vie annuel supérieur de $11 \%$ à la moyenne des actifs en emploi : $28300 €$, contre $25500 €$ toutes professions confondues (tableau 8) ${ }^{9}$.

8. Pour plus d'information sur la composition du revenu disponible des ménages en France, voir notamment la fiche «1.3. Revenu disponible des ménages » dans les Revenus et le patrimoine des ménages, Insee, coll. «Insee Références », édition 2014.

9. Pour davantage d'information sur les niveaux de vie en France, voir Cédric HoudRÉ, Juliette Ponceau, Marie Zergat Bonnin, les Niveaux de vie en 2012, Insee, coll. "Insee Première ", n 1513 , septembre 2014. 


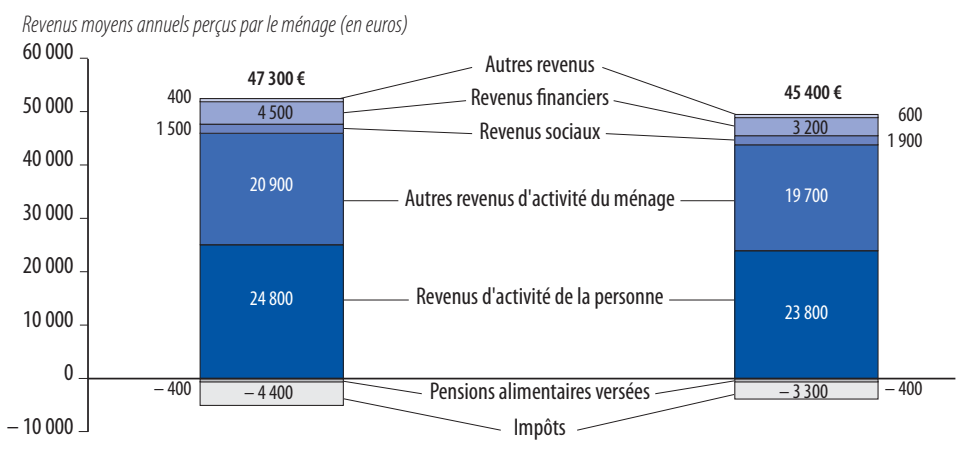

Ménages des professions de la culture

Ensemble des ménages d'actifs en emploi

Champ : ensemble des actifs en emploi principal, France métropolitaine.

Note de lecture : entre 2005 et 2012, un actif exerçant au titre d'emploi principal une profession culturelle vit dans un ménage dont le revenu annuel disponible s'élève en moyenne à $47300 €$. Celui-ci repose, en moyenne, sur des revenus d'activité de $24800 €$ provenant de l'activité du professionnel de la culture (96\% perçoivent des revenus d'activité strictement positifs d'un montant moyen de 26000 euros) et de $20900 €$ issus de l'activité des autres membres actifs du ménage. Les revenus sociaux s'établissent en moyenne à $1500 €$ pour l'ensemble des ménages des professionnels de la culture, les revenus financiers et fonciers à $4500 €$ et les autres revenus à $400 €$. Les ménages des professionnels de la culture paient en moyenne $4400 €$ dimpôts et versent en moyenne $400 €$ de pensions alimentaires.

Source : Enquête Revenus fiscaux et sociaux, Insee/DEPS, Ministère de la Culture et de la Communication, 2015

Tableau 8 - Niveau de vie annuel des actifs en emploi, 2005-2012

\begin{tabular}{|c|c|c|c|c|}
\hline & Moyenne & $\begin{array}{l}\text { Premier } \\
\text { décile }\end{array}$ & $\begin{array}{l}\text { Dernier } \\
\text { décile }\end{array}$ & \begin{tabular}{|c} 
Rapport \\
interdécile (D9/D1)
\end{tabular} \\
\hline Professions culturelles & 28300 & 13100 & 45300 & 3,5 \\
\hline Professions des arts visuels et des métiers d'art & t 23900 & 10900 & 38300 & 3,5 \\
\hline Professionnels des arts visuels & 24500 & 11400 & 39000 & 3,4 \\
\hline Métiers d'art & 20700 & 8900 & 34700 & 3,9 \\
\hline Professions du spectacle & 30200 & 14400 & 46500 & 3,2 \\
\hline Artistes des spectacles & 28800 & 13900 & 44500 & 3,2 \\
\hline Cadres artistiques, de programmation & & & & \\
\hline et de production des spectacles & 36600 & 16600 & 57700 & 3,5 \\
\hline Techniciens des spectacles & 26700 & 13900 & 41300 & 3,0 \\
\hline Professions littéraires & 31800 & 14000 & 52200 & 3,7 \\
\hline Journalistes et cadres de l'édition & 33100 & 14800 & 52500 & 3,5 \\
\hline Auteurs littéraires et traducteurs & 28400 & 10900 & 50900 & 4,7 \\
\hline Architectes & 35200 & 16400 & 58600 & 3,6 \\
\hline $\begin{array}{l}\text { Professions de l'archivage, de la conservation } \\
\text { et de la documentation }\end{array}$ & 30100 & 16100 & 46000 & 2,9 \\
\hline Professeurs d'art & 24800 & 11200 & 38700 & 3,4 \\
\hline Ensemble des actifs en emploi & 25500 & 13200 & 39700 & 3,0 \\
\hline \multicolumn{5}{|c|}{$\begin{array}{l}\text { Champ : ensemble des actifs en emploi principal, France métropolitaine. } \\
\text { Note de lecture : en moyenne annuelle entre } 2005 \text { et } 2012 \text {, un actif exerçant au titre de son emploi principal une profession culturelle a un niveau de vie de } \\
28300 € \text {. Un professionnel de la culture sur dix a un niveau de vie inférieur à } 13100 € \text {, un sur dix a un niveau de vie supérieur à } 45300 € \text { : soit un rapport } \\
\text { interdécile de } 3,5 \text {. }\end{array}$} \\
\hline
\end{tabular}


Au sein des professions culturelles, les niveaux de vie comme les revenus d'activité sont les plus faibles pour les professeurs d'art et les professionnels des arts visuels et des métiers d'art : en moyenne, ceux qui exercent un métier d'art ont un niveau de vie de $20700 €$, les professionnels des arts visuels et les professeurs d'art d'un peu moins de $25000 €$.

À l'opposé, les journalistes et cadres de l'édition (33 $100 €$ ) et, plus encore, les architectes (35 $200 €$ ) et les cadres artistiques, de programmation et de production des spectacles (36 $600 €$ ) ont les niveaux de vie les plus élevés.

Les auteurs littéraires et traducteurs, les artistes et les techniciens des spectacles et les professionnels de l'archivage, de la conservation et de la documentation se situent entre ces deux pôles.

\section{Une répartition plus inégalitaire dans les professions culturelles que dans l'ensemble}

Les niveaux de vie tenant compte des revenus complémentaires, à vocation notamment redistributive, ils sont globalement moins dispersés que les revenus d'activité, dans les professions culturelles (rapport interdécile de 3,5 contre 7,4 pour les revenus d'activité) comme dans l'ensemble des professions (rapport de 3,0 contre $4,7)$ : une redistribution se produit effectivement dans le passage du revenu d'activité au revenu disponible, grâce aux autres revenus du ménage (revenus du conjoint, transferts sociaux, revenus financiers et fonciers et autres revenus).

II n'en demeure pas moins que la répartition du niveau de vie des professionnels de la culture est un peu plus inégalitaire que celle de l'ensemble des actifs (rapport interdécile de 3,5 contre 3). En effet, chez les actifs qui exercent une profession culturelle, si les bas niveaux de vie sont équivalents à ceux de l'ensemble des professions (les $10 \%$ les moins favorisés ont un niveau de vie inférieur à $13100 €$, contre $13200 €$ dans l'ensemble), les hauts niveaux de vie y excèdent largement ceux des actifs les plus favorisés, toutes professions confondues (45 $300 €$ contre $39700 €$ ) (tableau 8).

Avec un rapport interdécile d'environ 3, les professionnels de l'archivage, de la conservation et de la documentation et les techniciens des spectacles ont un niveau de vie aussi dispersé que la moyenne. Les autres professions culturelles se caractérisent en revanche par une distribution moins équitable que celle de l'ensemble de la population active en emploi, avec un rapport interdécile compris entre 3,2 et 3,9. La distribution des niveaux de vie des auteurs littéraires et traducteurs est particulièrement inégalitaire : un sur dix dispose pour vivre de moins de $10900 €$ et, à l'autre extrémité de l'échelle des niveaux de vie, un sur dix plus de $50900 €$, soit un rapport interdécile de 4,7. Cette distribution des niveaux de vie est toutefois beaucoup moins inégalitaire que celle du revenu d'activité de ces professions, dont le rapport interdécile est proche de 16.

\section{Moyenne et dispersion des niveaux de vie : les professions culturelles loin de leurs groupes professionnels de référence}

Le montant moyen et la dispersion du niveau de vie permettent de distinguer quatre ensembles de professions culturelles.

- Le premier se caractérise par un niveau de vie moyen faible et assez fortement dispersé. Rassemblant $42 \%$ des professionnels de la culture, il est composé des professionnels des arts visuels, des métiers d'art et des professeurs d'art.

- Les auteurs littéraires et traducteurs constituent à eux seuls le deuxième ensemble ( $5 \%$ des professionnels de la culture) : leur niveau de vie moyen se situe dans la moyenne des professions culturelles mais se distingue par une distribution nettement plus inégalitaire.

- Un niveau de vie en moyenne plus élevé que la moyenne générale et modérément dispersé caractérise le troisième ensemble, composé des artistes et des techniciens 
des spectacles, ainsi que des professionnels de l'archivage, de la conservation et de la documentation ( $24 \%$ des professionnels de la culture).

- Les journalistes et cadres de l'édition, les architectes et les cadres artistiques, de programmation et de production des spectacles composent le dernier ensemble ( $29 \%$ des professionnels de la culture), qui dispose d'un niveau de vie nettement plus élevé que les trois précédents, en moyenne, et plus dispersé que celui de l'ensemble de actifs en emploi.

Ces quatre ensembles occupent des positions spécifiques par rapport aux groupes professionnels (voir « Définitions », p. 23) qui composent la population active en France, sous l'angle de la moyenne et de la dispersion des niveaux de vie (graphique 4).

Au sein du premier ensemble, les personnes exerçant un métier d'art ont un niveau de vie en moyenne inférieur à celui des artisans et des ouvriers qualifiés. De même, les professeurs d'art ont un niveau de vie moyen très en deçà de celui de leur groupe professionnel d'appartenance (les professeurs et professions scientifiques, parmi les cadres et professions intellectuelles supérieures). Ceux qui exercent un métier des arts visuels se situent entre le groupe professionnel des professions intermédiaires et celui des artisans, en termes de niveau de vie moyen.

En ce qui concerne le niveau de vie des auteurs littéraires et traducteurs, qui constituent le deuxième ensemble, son montant moyen les rapproche des commerçants, tandis que son hétérogénéité, très forte, les associe aux professions libérales et aux agriculteurs.

Au sein du troisième ensemble, le niveau de vie est en moyenne un peu plus élevé que dans l'ensemble des professions intermédiaires.

Enfin, le niveau de vie des professionnels du dernier ensemble se situe, en moyenne, en deçà de celui du groupe professionnel des cadres et professions intellectuelles supérieures (hors professions libérales) et s'en distingue par une dispersion plus forte. Il est à la fois nettement moindre et beaucoup moins dispersé que le niveau de vie des professions libérales et des chefs d'entreprise de plus de 10 salariés.

\section{Graphique 4 - Montant annuel moyen et dispersion du niveau de vie dans les professions culturelles et pour l'ensemble des actifs en emploi, 2005-2012}

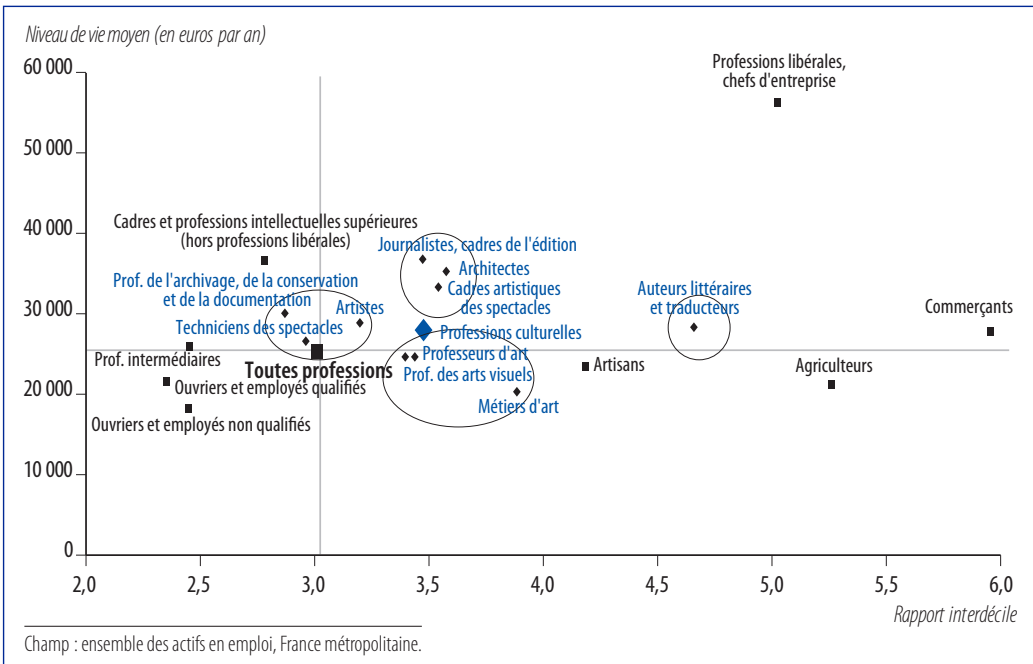




\section{Une fois les effets de structure pris en compte, les professionnels de la culture ont un niveau de vie inférieur à celui des autres actifs en emploi}

Les caractéristiques sociodémographiques et les conditions d'emploi des professionnels de la culture sont nettement distinctes de celles de la moyenne des actifs en emploi ${ }^{10}$, induisant des effets, parfois contradictoires, sur le niveau de vie des personnes. Majoritairement composées de cadres et professions intellectuelles supérieures, les professions culturelles sont exercées plus fréquemment sous statut indépendant par des actifs fortement diplômés et issus de milieux sociaux favorisés. Par ailleurs, les conditions de vie de ces actifs sont sensiblement différentes des autres: ils sont plus souvent locataires de leur logement, sont plus nombreux à résider à Paris ou dans sa région, vivent moins souvent en couple et ont moins d'enfants à charge. Or, d'une part, les cadres supérieurs, les non-salariés, les hommes, les actifs les plus diplômés, issus de milieux sociaux favorisés et les Franciliens perçoivent des revenus d'activité supérieurs aux autres, et, par suite, des revenus financiers et fonciers eux aussi plus élevés. D'autre part, une famille moins nombreuse induit de partager le revenu disponible du ménage entre un moins grand nombre de personnes; les locataires franciliens résidant dans une région où le coût du logement est élevé perçoivent davantage d'aides au logement et donc de prestations sociales. L'ensemble de ces caractéristiques tend par conséquent à tirer structurellement le niveau de vie des professionnels de la culture vers le haut.

À l'inverse, les professionnels de la culture ont des temps de travail plus courts ; ils vivent moins souvent que les autres en couple, ont moins souvent des enfants à charge. Or des temps de travail courts vont de pair avec des revenus d'activité moindres, l'absence d'un conjoint actif implique un revenu d'activité du ménage moins important, et une famille moins nombreuse induit de moindres prestations sociales. Ces caractéristiques contribuent donc à tirer le revenu disponible des professionnels de la culture vers le bas.

Ces effets de structure doivent être pris en compte afin de comparer de façon rigoureuse le niveau de vie des professionnels de la culture avec celui des autres actifs en emploi. Ainsi, alors que le niveau de vie de ces professionnels est de $11 \%$ supérieur, en moyenne, à celui de l'ensemble des actifs, si l'on tient compte de ces différentes caractéristiques en cherchant à neutraliser leur effet, le surcroît de niveau de vie des professionnels de la culture disparaît pour devenir négatif. À mêmes caractéristiques sociodémographiques et conditions d'emploi, un professionnel de la culture a en effet un niveau de vie inférieur en moyenne de $12 \%$ à celui d'un actif exerçant une autre profession. Pour les seuls revenus d'activité, l'écart « toutes choses égales par ailleurs » à la défaveur des professionnels de la culture est de $29 \%$. La prise en compte des autres revenus du ménage (revenus éventuels d'un conjoint, revenus financiers et fonciers, transferts sociaux, autres revenus) opère donc un rattrapage significatif (tableau 9).

\section{Comme pour l'ensemble des actifs, les femmes qui exercent une profession culturelle ont un niveau de vie comparable à celui des hommes}

Toutes professions confondues, avec $25000 €$ en moyenne annuelle au cours de la période 2005-2012, les femmes actives ont un niveau de vie pratiquement équivalent à celui des hommes actifs ${ }^{11}$ (25 $500 €$ ) (tableau 10). La prise en compte de l'ensemble des revenus du ménage conduit donc à gommer l'écart observé pour les revenus

10. M. Gouyon, F. Patureau, Vingt ans d'évolution de l'emploi dans les professions culturelles - 19912011, op. cit.

11. S. Ponthieux, "L'inégalité des revenus d'activité et les niveaux de vie des femmes et des hommes - Une comparaison entre cinq pays de l'Union européenne », op. cit. 
Tableau 9 - Déterminants du niveau de vie de l'ensemble des actifs en emploi, des professionnels de la culture, et des actifs exerçant une profession non culturelle, 2005-2012

\begin{tabular}{|c|c|c|c|c|}
\hline \multirow[b]{2}{*}{ Variable explicative } & Ensemble & $\begin{array}{l}\text { Professions } \\
\text { culturelles }\end{array}$ & $\begin{array}{c}\text { Professions } \\
\text { non culturelles }\end{array}$ & \multirow{2}{*}{$\begin{array}{c}\text { Test } \\
\text { de } \\
\text { différence }\end{array}$} \\
\hline & \multicolumn{3}{|c|}{$\begin{array}{l}\text { Effet marginal sur le niveau de vie } \\
\text { (en \%) en moyenne par rapport à la modalité de référence }\end{array}$} & \\
\hline $\begin{array}{l}\text { Domaine professionnel } \\
\text { Profession culturelle } \\
\text { Profession non culturelle }\end{array}$ & \multicolumn{3}{|l|}{$\begin{array}{r}-12 \\
\text { ref }\end{array}$} & \\
\hline \multicolumn{4}{|l|}{$\begin{array}{l}\text { Catégorie sociale } \\
\text { Cadres et professions intellectuelles supérieures } \\
\text { Autre catégorie socioprofessionnelle }\end{array}$} & +++ \\
\hline $\begin{array}{l}\text { Statut d'activité } \\
\text { Salarié } \\
\text { Non-salarié }\end{array}$ & $\begin{array}{l}+2 \\
\text { ref }\end{array}$ & $\begin{array}{r}+20 \\
r e f\end{array}$ & $\begin{array}{c}+1 \\
\text { ref }\end{array}$ & +++ \\
\hline $\begin{array}{l}\text { Temps de travail hebdomadaire } \\
\text { Moins de } 20 \text { heures } \\
\text { De } 20 \text { à } 31 \text { heures } \\
\text { De } 32 \text { à } 37 \text { heures } \\
\text { De } 38 \text { à } 41 \text { heures } \\
42 \text { heures ou + }\end{array}$ & $\begin{array}{r}-13 \\
-4 \\
r e f \\
+3 \\
+6\end{array}$ & $\begin{array}{r}-17 \\
-9 \\
r e f \\
+4 \\
+10\end{array}$ & $\begin{array}{r}-13 \\
-4 \\
r e f \\
+3 \\
+6\end{array}$ & $\begin{array}{c}+ \\
++ \\
\text { ns } \\
+\end{array}$ \\
\hline $\begin{array}{l}\text { Sexe } \\
\text { Homme } \\
\text { Femme }\end{array}$ & $\begin{array}{r}\text { ref } \\
+3\end{array}$ & $\begin{array}{l}r e f \\
+3\end{array}$ & $\begin{array}{r}r e f \\
+3\end{array}$ & ns \\
\hline $\begin{array}{l}\text { Age } \\
\text { Moins de } 40 \text { ans } \\
40 \text { ans ou }+\end{array}$ & $\begin{array}{c}-6 \\
\text { ref }\end{array}$ & $\begin{array}{l}-4 \\
\text { ref }\end{array}$ & $\begin{array}{l}-6 \\
\text { ref }\end{array}$ & ns \\
\hline $\begin{array}{l}\text { Milieu social d'origine } \\
\text { Père cadre (supérieur ou intermédiaire) } \\
\text { Père d'une autre catégorie sociale }\end{array}$ & $\begin{array}{r}r e f \\
+15\end{array}$ & $\begin{array}{r}r e f \\
+7\end{array}$ & $\begin{array}{r}r e f \\
+15\end{array}$ & +++ \\
\hline $\begin{array}{l}\text { Niveau de diplôme } \\
\text { Bac }+2 \text { ou moins } \\
\mathrm{Bac}+3 \text { ou plus }\end{array}$ & $\begin{array}{c}+7 \\
\text { ref }\end{array}$ & $\begin{array}{c}+3 \\
\text { ref }\end{array}$ & $\begin{array}{c}+7 \\
\text { ref }\end{array}$ & +++ \\
\hline $\begin{array}{l}\text { Lieu de résidence } \\
\text { Commune francilienne } \\
\text { Autre commune rurale } \\
\text { Autre commune urbaine }\end{array}$ & $\begin{array}{r}+17 \\
r e f \\
+5\end{array}$ & $\begin{array}{r}+28 \\
r e f \\
+7\end{array}$ & $\begin{array}{r}+16 \\
r e f \\
+5\end{array}$ & +++ \\
\hline $\begin{array}{l}\text { Statut vis-à-vis du logement } \\
\text { Propriétaire } \\
\text { Locataire } \\
\text { Logé à titre gratuit }\end{array}$ & $\begin{array}{r}r e f \\
-26 \\
-18\end{array}$ & $\begin{array}{r}r e f \\
-25 \\
-32\end{array}$ & $\begin{array}{r}r e f \\
-26 \\
-18\end{array}$ & $\begin{array}{c}\text { ns } \\
+++\end{array}$ \\
\hline $\begin{array}{l}\text { Vie de famille } \\
\text { En couple avec enfant(s) } \\
\text { En couple sans enfant } \\
\text { Famille monoparentale } \\
\text { Seul sans enfant }\end{array}$ & $\begin{array}{r}-20 \\
r e f \\
-24 \\
-24\end{array}$ & $\begin{array}{r}-14 \\
r e f \\
-24 \\
-35\end{array}$ & $\begin{array}{r}-20 \\
r e f \\
-24 \\
-23\end{array}$ & +++ \\
\hline \multicolumn{5}{|c|}{ 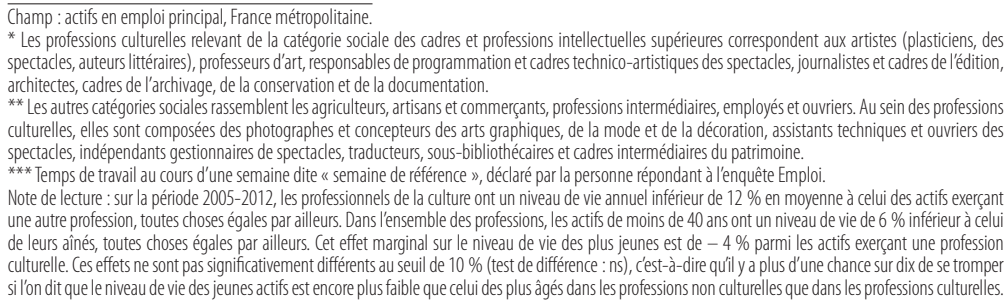 } \\
\hline
\end{tabular}


d'activité, très nettement défavorable aux femmes (- $29 \%)$. Ce constat est confirmé une fois les effets de structure neutralisés: à mêmes conditions d'emploi et autres caractéristiques sociodémographiques identiques, les femmes ont un niveau de vie très légèrement supérieur $(+3 \%)$ à celui des hommes.

Entre 2005 et 2012, les professionnelles de la culture ont un niveau de vie de $28800 €$ en moyenne, supérieur de $5 \%$ à celui de leurs homologues masculins (tableau 10). On peut vraisemblablement attribuer cet écart positif au fait que les professionnelles de la culture sont nettement plus souvent en couple avec un conjoint occupant une position de cadre (supérieur ou intermédiaire : $73 \%$ ) que l'inverse (59\% des hommes en couple exerçant une profession culturelle vivent avec un conjoint cadre) (voir tableau A, p. 26), et qui apporte donc au ménage des revenus d'activité complémentaire plus élevés. Cet écart positif entre le niveau de vie des femmes et des hommes est particulièrement important dans les professions des arts visuels, parmi les auteurs littéraires et les professeurs d'art, où l'on peut supposer que les revenus d'activité du conjoint sont supérieurs aux revenus d'activité que les femmes perçoivent pour leur propre compte. En raisonnant à structure constante, l'écart passe de $5 \%$ à $3 \%$, c'est-à-dire rejoint celui observé dans les autres professions.

Tableau 10 - Niveau de vie annuel moyen des femmes et des hommes actifs en emploi, 2005-2012

\begin{tabular}{|c|c|c|c|}
\hline & Hommes & Femmes & $\begin{array}{c}\text { Écart femmes/hommes } \\
\text { (en \%) }\end{array}$ \\
\hline Professions culturelles & 27500 & 28800 & 5 \\
\hline Professions des arts visuels et des métiers d'art & 22800 & 25000 & 10 \\
\hline Professionnels des arts visuels & 23000 & 26000 & 13 \\
\hline Métiers d'art & 21600 & 19600 & -9 \\
\hline Professions du spectacle & 29400 & 31000 & 6 \\
\hline Artistes des spectacles & 28000 & 29500 & 5 \\
\hline Cadres artistiques, de programmation & & & \\
\hline et de production des spectacles & 35900 & 35600 & -1 \\
\hline Techniciens des spectacles & 26100 & 27400 & 5 \\
\hline Professions littéraires & 30300 & 33000 & 9 \\
\hline Journalistes et cadres de l'édition & 32200 & 33300 & 3 \\
\hline Auteurs littéraires et traducteurs & 25800 & 32300 & 26 \\
\hline Architectes & 35500 & 33900 & -4 \\
\hline $\begin{array}{l}\text { Professions de l'archivage, de la conservation } \\
\text { et de la documentation }\end{array}$ & 28900 & 30400 & 5 \\
\hline Professeurs d'art & 22300 & 26500 & 19 \\
\hline Ensemble des actifs en emploi & 25500 & 25000 & -2 \\
\hline
\end{tabular}

Source : Enquête Revenus fiscaux et sociaux, Insee/DEPS, Ministère de la Culture et de Communication, 2015 


\section{Sources : L'enquête Revenus fiscaux et sociaux de l'Insee}

Les statistiques présentées ici s'appuient sur l'enquête Revenus fiscaux et sociaux de I'Insee, disponible chaque année depuis 2005 et fondée sur un échantillon représentatif des ménages en France métropolitaine, issu de l'enquête Emploi, mais aussi sur leurs déclarations fiscales et sur les prestations qu'ils ont perçues de la part de la Caisse nationale des allocations familiales (Cnaf), de la Caisse nationale d'assurance vieillesse (Cnav) ou de la Mutualité sociale agricole (MSA).

Les revenus déclarés à l'administration fiscale comprennent les revenus directs d'activité indépendante ou salariée, les retraites et pensions, les indemnités de chômage, les revenus du patrimoine.

La présente étude repose sur la fusion de huit enquêtes consécutives, de 2005 à 2012, afin de disposer d'effectifs suffisamment importants et de garantir la robustesse et la fiabilité des résultats sur le champ restreint que constituent les professions culturelles. L'échantillon est constitué de 330135 observations portant sur les actifs en emploi, parmi lesquels 6557 exercent une profession culturelle, entre 2005 et 2012. On raisonne ainsi en moyenne annuelle sur huit années. Les revenus relatifs à chaque année d'enquête ont été déflatés et ramenés à la devise de la dernière année: les revenus présentés dans cette étude sont donc en euros constants de 2012.

\section{Définitions}

\section{L'EMPLOI}

\section{Emploi principal}

La plupart des actifs exercent un seul métier tout au long de l'année - éventuellement sur plusieurs postes de travail concomitants ou successifs. Certains toutefois en exercent plusieurs. C'est à celui qu'ils considèrent comme principal en termes de temps de travail ou de revenus que s'intéresse cette étude.

\section{Groupe professionnel}

Les groupes professionnels auxquels les professions culturelles sont comparées sont définis à partir de la catégorie socioprofessionnelle (code à deux chiffres de la nomenclature des Professions et catégories socioprofessionnelles, PCS).

Les catégories sociales proches les unes des autres, du point de vue de la moyenne et de la dispersion des revenus d'activité, ont été regroupées pour davantage de clarté (notamment graphique). On définit ainsi les groupes professionnels suivants.

- Les agriculteurs sont agriculteurs exploitants, quelle que soit la taille de l'exploitation.

- Les artisans mettent en valeur un capital économique en tant que chef de leur propre entreprise, mais travaillent seuls ou n'emploient qu'un petit nombre de salariés, dans un domaine où le travail manuel est un aspect important.

- Les commerçants mettent eux aussi en valeur un capital économique en tant que chef de leur propre entreprise, en travaillant seuls ou en n'employant qu'un petit nombre de salariés, mais dans un domaine où le travail manuel est un aspect secondaire et qui n'exige pas un capital culturel très élevé.

- Le groupe professionnel des professions libérales et chefs d'entreprise de plus de dix salariés rassemble avocats, médecins libéraux, architectes libéraux, notaires, chefs d'entreprise de plus de dix salariés, etc.

- Le groupe professionnel des cadres et professions intellectuelles supérieures (hors professions libérales) est composé des cadres A de la fonction publique, ingénieurs, cadres commerciaux d'entreprise, artistes, professeurs, professions scientifiques, etc.

- Les professions intermédiaires rassemblent instituteurs, infirmiers, cadres B de la fonction publique, techniciens, contremaîtres, secrétaires de direction, etc. 
- Le groupe professionnel des ouvriers et employés non qualifiés regroupe des professions qui cumulent bas niveau de qualification dans les conventions collectives, faibles salaires et formations peu spécialisées ${ }^{12}$, tels qu'agents des services de la fonction publique, employés de l'hôtellerie-restauration, caissiers et employés de libre-service du commerce, salariés de particuliers, concierges et vigiles, manutentionnaires et agents du tri, ouvriers d'entretien, ouvriers non qualifiés de l'industrie et du BTP, ouvriers agricoles.

- Le groupe professionnel des ouvriers et employés qualifiés est défini en négatif du précédent.

\section{Profession culturelle}

Le terme de « profession » est employé ici de façon générique (et indifféremment à celui de « métier »), par référence à la nomenclature des Professions et catégories socioprofessionnelles (PCS) qui sert de cadre à la présente analyse. II ne renvoie donc pas aux seules activités professionnelles formellement encadrées et réglementées (la profession d'architecte ou celle de conservateur, par exemple), plutôt minoritaires dans le champ culturel, mais à l'ensemble particulièrement hétérogène des activités professionnelles (au sens anglo-saxon d'occupations) relevant du champ d'intervention du ministère de la Culture et de la Communication.

Les professions culturelles sont définies à partir de la nomenclature de 2003 des professions et catégories socioprofessionnelles (PCS), dont sont retenus les codes suivants:

\section{Professions des arts visuels}

$354 \mathrm{~A}$ Artistes plasticiens

465C Photographes

465A Concepteurs et assistants techniques

des arts graphiques, de la mode et de la décoration

\section{Professions des arts visuels et métiers d'art}

\section{Métiers d'art}

214E Artisans d'art

637B Ouvriers d'art

\section{Professions des spectacles}

\section{Artistes des spectacles}

354B Artistes de la musique et du chant

$354 C$ Artistes dramatiques

354D Artistes de la danse, du cirque et des spectacles divers

Techniciens des spectacles

465B Assistants techniques

637C Ouvriers et techniciens

Cadres artistiques, de programmation

et de production des spectacles

353B Directeurs, responsables de programmation et de production

353C Cadres artistiques et technico-artistiques

227A Indépendants gestionnaires de spectacles ou de services récréatifs

\section{Professions littéraires}

\section{Journalistes et cadres de l'édition}

$352 \mathrm{~A}$ Journalistes et rédacteurs en chef

353A Directeurs de journaux, administrateurs de presse, directeurs d'édition
Auteurs littéraires et traducteurs

352B Auteurs littéraires, scénaristes, dialoguistes

464B Traducteurs et interprètes

\section{Architectes}

312F Architectes libéraux

382B Architectes salariés

\section{Professions de la documentation, de l'archivage et de la conservation}

351A Bibliothécaires, archivistes, conservateurs, de la fonction publique

372F Cadres de la documentation, de l'archivage (hors fonction publique)

\section{Professeurs d'art (hors établissements scolaires)}

354G Professeurs d'art (hors établissements scolaires d'enseignement général)

12. Thomas AmossÉ, Olivier CHARDON, « Les travailleurs non qualifiés : une nouvelle classe sociale ? », Insee, «Économie et Statistique », n 393-394, 2006. 


\section{LES REVENUS}

Tous les revenus analysés dans la présente étude sont nets de cotisations sociales.

\section{Revenus d'activité}

On regroupe sous le terme de « revenus d'activité » les revenus directs d'activité (salaires et revenus d'indépendants) et les revenus de remplacement (pensions de retraite, indemnités de chômage). Les revenus d'activité peuvent être négatifs ou nuls si l'activité est déficitaire.

\section{Traitements et salaires}

Du point de vue fiscal (imprimé n 2042 de la DGFIP), sont déclarées dans la catégorie des traitements et salaires:

- les rémunérations issues d'un emploi salarié, caractérisé par un lien de subordination vis-àvis d'un employeur ;

- une partie des revenus d'indépendants : les écrivains et compositeurs sont en effet imposés dans cette catégorie quand les droits d'auteur qui leur sont versés sont intégralement déclarés par des tiers (maison d'édition, société d'auteurs telle que la Sacem, la SACD etc.) ;

- les allocations de chômage, les allocations de préretraite et les indemnités journalières de maladie.

Dans notre étude, les indemnités de chômage et les allocations de préretraite (considérées comme des revenus de remplacement, au même titre que les pensions de retraite) sont dissociées des autres traitements et salaires (que l'on considère comme des revenus directs d'activité).

\section{Revenus d'indépendants}

Les revenus d'indépendants regroupent les revenus non commerciaux, les revenus industriels et commerciaux et les revenus agricoles, réalisés en France et déclarés fiscalement en bénéfices non commerciaux (BNC), bénéfices industriels et commerciaux (BIC) et bénéfices agricoles (BA).

Dans la déclaration des revenus, sont imposés en bénéfices non commerciaux (BNC) les bénéfices réalisés:

- par les professionnels qui pratiquent une science, un art ou une activité intellectuelle en toute indépendance (médecins, avocats, architectes, experts-comptables, artistes, etc.) ; - par les titulaires de charges et offices publics (notaires, commissaires-priseurs, etc.).

Les BNC regroupent également diverses rémunérations qui ne sont pas imposées dans une autre catégorie de l'impôt sur le revenu telles que les droits d'auteur (sauf s'ils sont déclarés par un tiers, voir supra) et les produits de la propriété intellectuelle.

Les bénéfices industriels et commerciaux sont les bénéfices réalisés par des personnes physiques ou par des sociétés soumises à l'impôt sur le revenu, provenant de l'exercice d'une profession commerciale, industrielle ou artisanale. coles.

Les revenus d'origine agricole sont quant à eux imposés fiscalement en bénéfices agri-

\section{Revenus sociaux}

Les prestations sociales sont de trois ordres:

- les prestations familiales, issues des fichiers sociaux de la Cnaf ou de la caisse centrale de la MSA, regroupent des aides liées au jeune enfant (dispositif dénommé Prestation d'accueil du jeune enfant [Paje] : prime à la naissance ou à l'adoption, allocation de base de la Paje, complément de libre choix d'activité, complément optionnel de libre choix d'activité) ainsi que les prestations familiales suivantes: allocation familiale (AF), complément familial (CF), allocation d'éducation de l'enfant handicapé (AEEH), allocation de soutien familial (ASF), allocation de rentrée scolaire (ARS), allocation journalière de présence parentale (AJPP) ;

- les minima sociaux, versés par la Cnaf, la CCMSA ou la Cnav, correspondent aux prestations suivantes : revenu de solidarité active (le RSA a remplacé le revenu minimum d'insertion [RMI] et l'allocation de parent isolé [API] à compter du $1^{\text {er }}$ juin 2009), prime de Noël, allocation adultes handicapés (AAH), allocations complémentaires à l'allocation adultes handicapés (CAAH), minimum vieillesse (ASPA) ;

- les aides au logement sont destinées à alléger les charges de remboursement des personnes qui accèdent à la propriété ou les charges de loyer des locataires. II existe trois types 
d'allocation logement (dont les conditions d'attribution varient selon le statut des bénéficiaires) : aide personnalisée au logement (APL), allocation logement à caractère familial (ALF), allocation logement à caractère social (ALS).

\section{Revenus financiers et fonciers}

Les revenus financiers correspondent aux produits dont les revenus sont issus de la source fiscale, tels qu'intérêts des actions, des livrets fiscalisés et des autres valeurs mobilières (obligations, placements à échéance, titres d'OPCVM). Ils correspondent également aux intérêts générés par différents produits financiers non recensés par la source fiscale: il s'agit des intérêts des livrets d'épargne exonérés (livret Jeune, livret d'épargne populaire [LEP] et autres livrets exonérés tels que livret A, livret bleu et livret pour le développement durable [LDD, anciennement CODEVI]), des formules d'épargne logement (comptes et plans d'épargne logement [CEL et PEL]), des produits du groupe assurance vie (contrats d'assurance vie, plan d'épargne populaire [PEP], bons de capitalisation) ainsi que des valeurs mobilières en plan d'épargne en actions (PEA). Pour imputer ces revenus défiscalisés, l'enquête Revenus fiscaux et sociaux s'appuie sur l'enquête Patrimoine de l'Insee.

Les revenus fonciers sont les revenus procurés aux propriétaires d'immeubles bâtis ou non bâtis, hors les revenus procurés par la location d'habitations meublées, d'usines, ateliers, fonds de commerce.

\section{Autres revenus}

Ces revenus regroupent des revenus d'autre nature que ceux énoncés précédemment : il s'agit principalement de la prime pour l'emploi, qui est un crédit d'impôt attribué aux foyers fiscaux dont l'un des membres au moins exerce une activité professionnelle et dont les revenus

Tableau A - Caractéristiques sociodémographiques et conditions d'emploi des professionnels de la cult

\begin{tabular}{|c|c|c|c|c|c|c|c|c|}
\hline & \multirow{3}{*}{ Effectifs } & \multirow{3}{*}{ Femmes } & & & & & & \\
\hline & & & \multicolumn{2}{|c|}{ Âge } & \multirow{2}{*}{$\begin{array}{l}\text { Père } \\
\text { cadre }\end{array}$} & \multicolumn{3}{|c|}{$\mathrm{Bac}+3 \mathrm{ou}+$} \\
\hline & & & $\begin{array}{l}\text { Moins } \\
\text { de } 40 \text { ans }\end{array}$ & $\begin{array}{c}65 \text { ans } \\
\text { et }+\end{array}$ & & Ensemble & $\begin{array}{l}\text { Parmiles } \\
\text { hommes }\end{array}$ & $\begin{array}{l}\text { Parmiles } \\
\text { femmes }\end{array}$ \\
\hline Professions culturelles & 573000 & 43 & 48 & 3 & 52 & 41 & 37 & 47 \\
\hline Professions des arts visuels et des métiers d'art & 194300 & 46 & 51 & 4 & 47 & 26 & 24 & 29 \\
\hline Professionnels des arts visuels & 164100 & 47 & 54 & 4 & 49 & 29 & 29 & 29 \\
\hline Métiers d'art & 30200 & 39 & 33 & 1 & 35 & 13 & 3 & 28 \\
\hline Professions du spectacle & 166000 & 33 & 53 & 1 & 53 & 32 & 27 & 44 \\
\hline Artistes des spectacles & 62600 & 36 & 51 & 2 & 51 & 31 & 25 & 42 \\
\hline Cadres artistiques, de programmation & & & & & & & & \\
\hline et de production des spectacles & 53300 & 36 & 46 & 1 & 56 & 44 & 39 & 53 \\
\hline Techniciens des spectacles & 50100 & 26 & 65 & 0 & 52 & 21 & 17 & 32 \\
\hline Professions littéraires & 88600 & 48 & 44 & 5 & 62 & 66 & 65 & 67 \\
\hline Journalistes et cadres de l'édition & 62800 & 45 & 47 & 4 & 63 & 67 & 66 & 67 \\
\hline Auteurs littéraires et traducteurs & 25800 & 53 & 37 & 8 & 58 & 65 & 63 & 67 \\
\hline Architectes & 51700 & 33 & 42 & 5 & 57 & 78 & 73 & 88 \\
\hline $\begin{array}{l}\text { Professions de I'archivage, de la conservation } \\
\text { et de la documentation }\end{array}$ & 25900 & 76 & 32 & 2 & 52 & 68 & 66 & 69 \\
\hline Professeurs d'art & 46500 & 50 & 43 & 3 & 49 & 35 & 29 & 40 \\
\hline Ensemble des actifs en emploi & 25741600 & 48 & 45 & 1 & 27 & 19 & 18 & 20 \\
\hline
\end{tabular}


ne dépassent pas certaines limites. Ils peuvent également correspondre à des revenus reçus de l'étranger et imposés à l'étranger, ou à des pensions alimentaires reçues.

\section{REVENU DISPONIBLE ET NIVEAU DE VIE}

\section{Ménage}

Dans l'enquête Revenus fiscaux et sociaux, le ménage désigne l'ensemble des occupants d'une résidence principale qu'ils aient ou non des liens de parenté. Le ménage peut ne comprendre qu'une seule personne.

\section{Revenu disponible}

Il comprend les revenus d'activité, les revenus sociaux, les revenus financiers et fonciers, et d'autres revenus éventuellement perçus par le ménage. Tous ces revenus sont nets des cotisations sociales (contribution sociale généralisée, contribution à la réduction de la dette sociale, prélèvement libératoire sur valeurs mobilières et autres prélèvements sociaux sur les revenus du patrimoine). Pour obtenir le revenu disponible, les revenus supra sont diminués de l'impôt sur le revenu et de la taxe d'habitation sur la résidence principale.

\section{Unité de consommation}

Les unités de consommation (UC) sont calculées selon l'échelle d'équivalence dite de l'OCDE modifiée, qui attribue 1 UC au premier adulte du ménage, 0,5 UC aux autres personnes de 14 ans ou plus et 0,3 UC aux enfants de moins de 14 ans.

\section{Niveau de vie}

Le niveau de vie correspond au revenu disponible du ménage divisé par le nombre d'unités de consommation, il est donc le même pour toutes les personnes d'un même ménage.

\begin{tabular}{|c|c|c|c|c|c|c|c|c|c|c|c|c|}
\hline \multicolumn{9}{|c|}{ Caractéristiques sociodémographiques } & \multicolumn{4}{|c|}{ Conditions d'emploi } \\
\hline \multirow{2}{*}{$\begin{array}{l}\text { Résidents } \\
\text { en Île- } \\
\text { de-France }\end{array}$} & \multirow{2}{*}{$\begin{array}{l}\text { Propriétaire } \\
\text { de son } \\
\text { logement }\end{array}$} & \multicolumn{3}{|c|}{ En couple } & \multicolumn{3}{|c|}{ dont : avec un/une cadre ${ }^{*}$} & \multirow{2}{*}{$\begin{array}{c}\text { Avec } \\
\text { enfants } \\
\text { à charge }\end{array}$} & \multirow[t]{2}{*}{$\begin{array}{l}\text { \% Non } \\
\text { salariés }\end{array}$} & \multicolumn{3}{|c|}{$\begin{array}{l}\text { Temps de travail moyen } \\
\text { (h/semaine) }\end{array}$} \\
\hline & & Ensemble & $\begin{array}{l}\text { Parmi les } \\
\text { hommes }\end{array}$ & $\begin{array}{l}\text { Parmiles } \\
\text { femmes }\end{array}$ & Ensemble & $\begin{array}{l}\text { Parmi les } \\
\text { hommes }\end{array}$ & $\begin{array}{l}\text { Parmi les } \\
\text { femmes }\end{array}$ & & & Ensemble & $\begin{array}{l}\text { Parmiles } \\
\text { hommes }\end{array}$ & $\begin{array}{l}\text { Parmiles } \\
\text { femmes }\end{array}$ \\
\hline 42 & 56 & 67 & 67 & 67 & 65 & 59 & 73 & 48 & 33 & 36,1 & 37,8 & 33,9 \\
\hline 39 & 54 & 67 & 66 & 69 & 62 & 57 & 66 & 48 & 51 & 38,0 & 39,7 & 36,0 \\
\hline 42 & 52 & 68 & 67 & 69 & 65 & 62 & 67 & 48 & 51 & 37,5 & 39,1 & 35,7 \\
\hline 24 & 62 & 66 & 65 & 67 & 45 & 35 & 60 & 47 & 53 & 40,8 & 42,6 & 38,0 \\
\hline 48 & 55 & 65 & 65 & 64 & 63 & 58 & 72 & 44 & 15 & 34,9 & 35,8 & 33,0 \\
\hline 41 & 55 & 63 & 63 & 63 & 75 & 71 & 81 & 42 & 17 & 28,6 & 30,0 & 26,3 \\
\hline 57 & 61 & 68 & 70 & 64 & 61 & 54 & 76 & 47 & 23 & 41,7 & 42,8 & 39,7 \\
\hline 48 & 49 & 63 & 63 & 64 & 49 & 48 & 50 & 44 & 5 & 35,5 & 35,8 & 34,9 \\
\hline 54 & 51 & 66 & 68 & 64 & 73 & 65 & 82 & 46 & 28 & 37,7 & 39,3 & 36,0 \\
\hline 59 & 53 & 65 & 66 & 63 & 74 & 65 & 85 & 47 & 12 & 39,6 & 40,8 & 38,1 \\
\hline 42 & 48 & 70 & 72 & 68 & 70 & 64 & 76 & 45 & 67 & 33,2 & 34,9 & 31,7 \\
\hline 36 & 66 & 78 & 82 & 69 & 68 & 62 & 83 & 55 & 56 & 43,8 & 45,9 & 39,8 \\
\hline 34 & 67 & 62 & 60 & 63 & 73 & 50 & 79 & 48 & 0 & 33,7 & 35,5 & 33,2 \\
\hline 26 & 65 & 69 & 63 & 75 & 67 & 62 & 70 & 51 & 19 & 22,3 & 24,4 & 20,2 \\
\hline 20 & 61 & 74 & 76 & 72 & 40 & 35 & 45 & 59 & 12 & 36,8 & 39,7 & 33,7 \\
\hline
\end{tabular}




\section{Abstract}

\section{Income and living standards for cultural professionals}

In France, 2.2\% of the working population work in the cultural professions. The cultural professions cover an exceptionally wide range of jobs (skilled artisans, art teachers, theatrical technicians and artists, architects and publishing executives, etc.) their wage structures and sums also vary considerably from one profession to the next: salaries, self-employed income, as well as income substitution benefits such as unemployment benefit or even, for certain sections of the working population, retirement pensions. Using various editions of the INSEE Tax and Social Incomes Survey, it is possible to get an overview of average annual incomes in this sector as well as income support.

Although the average annual salaries drawn by professionals in the cultural field are generally equivalent to those of the working population as a whole, income support on the other hand accounts for a far greater proportion of their income. Between 2005 and 2012, those working in the cultural professions earned an average total annual wage of $€ 26,000$. This is $6 \%$ higher than the average for the working population as a whole.

However, their defining sociodemographic features and their employment terms (qualifications, working time, etc) for cultural professionals are very different to those of other workers. Matching like-for-like, cultural professionals actually earn 26\% less than those in other jobs.

The make-up of the household, family history, income from other household members (usually a partner), complete their earnings. Earnings from other household members tend to be higher (by 16\%) for those working in the cultural sphere than for those working in other sectors $(€ 30,200$ per annum). Moreover, households for those working in the cultural sphere have rates of social, financial or land-based income some 13\% higher, on average, than the working population as a whole (€6800 per annum).

When applied to all household members, all of these revenues totalled defines their standard of living. Between 2005 and 2012, the average standard of living for cultural professionals was $€ 28,300$ per annum, some $11 \%$ higher than that for other professions; again however, when comparing like-for-like, it is actually 12\% lower than those of workers in other professions.

Within the cultural professions, the income gap between men and women is 19\% (in men's favour), and 29\% for the working population as a whole. Taking additional household income into account, particularly that from partners, helps to even out this male-female income gap: the standard of living for working women, whether they work in the cultural professions or not, is very similar to that of men.

Directeur de la publication : Xavier Niel

Responsable de la publication : Edwige Millery

\section{Retrouvez l'ensemble des publications du DEPS sur : http://www.culturecommunication.gouv.fr/Etudes-et-statistiques et sur http://www.cairn.info}

Le DEPS n'assurant pas de diffusion physique de ses collections de synthèse, nous vous proposons de vous informer régulièrement des parutions par message électronique.

Pour ce faire, merci de bien vouloir nous communiquer votre courriel à l'adresse contact.deps@culture.gouv.fr 
